Check for updates

Cite this: RSC Adv., 2020, 10, 13050

Received 19th December 2019

Accepted 2nd March 2020

DOI: $10.1039 / c 9 r a 10719 c$

rsc.li/rsc-advances

\section{Colorimetric sensing of chlorpyrifos through negative feedback inhibition of the catalytic activity of silver phosphate oxygenase nanozymes $\uparrow$}

\begin{abstract}
Amisha Kushwaha, Gajendar Singh and Manu Sharma (DD *
Intensive use of organophosphate chlorpyrifos pesticides in farming has become a serious issue due to their harmful effects on living beings. Most fruits, vegetables and soil contain chlorpyrifos, and it cannot be rinsed out completely by water washing. Therefore, a selective and sensitive detection of chlorpyrifos is significant. In the present study, the intriguing oxidase-mimicking activity of $\mathrm{Ag}_{3} \mathrm{PO}_{4}$ nanoparticles (NPs) is explored for the fast and selective detection of chlorpyrifos pesticides. $\mathrm{Ag}_{3} \mathrm{PO}_{4} \mathrm{NPs}$ exhibit several advantages, such as great catalytic efficiency, high stability, monodispersity and reusability, over other expensive nanozymes via a facile one-step sensing. The size, shape, crystal planes and diffraction patterns of the $\mathrm{Ag}_{3} \mathrm{PO}_{4} \mathrm{NPs}$ were observed via FESEM and HR-TEM. The surface properties and oxidation states were analyzed via XPS technique. $\mathrm{Ag}_{3} \mathrm{PO}_{4} \mathrm{NPs}$ possess intrinsic excellent oxidase-mimicking properties against $3,3^{\prime}, 5,5^{\prime}$ tetramethylbezidyne (TMB). When chlorpyrifos and $\mathrm{Ag}_{3} \mathrm{PO}_{4} \mathrm{NP}$ nanozymes come in proper orientation proximity, chlorpyrifos is oxidized. The oxidized chlorpyrifos produces sulfide ions and chlorpyrifos oxon. The produced sulfide ions in the reaction system interact with $\mathrm{Ag}_{3} \mathrm{PO}_{4} \mathrm{NPs}$ and inhibit their catalytic activity by feedback inhibition. Indeed, neither any catalytic site is left to oxidize TMB nor any blue colour appears. Thus, this feedback inhibition phenomenon senses chlorpyrifos pesticides. The calculated limit of detection (LOD) for the standard chlorpyrifos is $\sim 9.97 \mathrm{ppm}$, and the efficacy of the $\mathrm{Ag}_{3} \mathrm{PO}_{4} \mathrm{NPs}$ calculated in terms of the $K_{\mathrm{m}}$ value was found to be $0.15 \mathrm{mM}$. A real sample analysis was carried out by the standard addition method with two soil samples collected from Pethapur and Chiloda villages.
\end{abstract}

\section{Introduction}

Over the last few decades, the monitoring of hazardous chlorpyrifos in the natural ecosystem has become a serious issue. Pesticides show harmful and adverse effects on human health and on the healthy environment of flora and fauna. Pesticides are used to control undesirable herbs, plants, insects, fungi, nematodes, rodents, fish, bugs, microbes, etc. The organophosphate chlorpyrifos is harmful to directly touch, inhale or eat. Its insecticidal action causes the inhibition of the nerve enzyme acetylcholinesterase; consequently, the neurotransmitter acetylcholine accumulates at nerve endings. ${ }^{1}$ Nerve enzyme acetylcholinesterase metabolises the neurotransmitter acetylcholine into choline and acetate in a hydrolytic manner. Chlorpyrifos has a broad spectrum activity that affects the nervous systems of humans, animals and targeted pests by progressively inhibiting acetylcholinesterase, which leads to the loss of sensation. ${ }^{2}$ Exposure to even a small amount can cause tears, runny nose, and increased saliva or drooling symptoms in

Central University of Gujarat, Gandhinagar, Gujarat-382030, India. E-mail: manu. sharma@cug.ac.in

$\dagger$ Electronic supplementary information (ESI) available. See DOI: 10.1039/c9ra10719c. minutes or an hour. An initial exposure of chlorpyrifos in its complete molecular state form is non-toxic, and as such it moves to all parts of the body. After the oxidation of chlorpyrifos in the body, the toxic chlorpyrifos oxon and sulfide ions are produced. ${ }^{3}$ Then, chlorpyrifos permanently binds acetylcholinesterase and blocks its activity. ${ }^{4}$ Chlorpyrifos is also very toxic to bird species, such as pigeons and grackles, and is moderately toxic to mallard ducks. ${ }^{4}$ When mallard ducks feed on chlorpyrifos, they lay fewer eggs and fewer ducklings are born. ${ }^{5}$ The eggshells also become thinner than normal, and many of the young ducklings die. ${ }^{6}$ Among all birds, robins show the highest mortality from chlorpyrifos exposure. Chlorpyrifos is also very toxic to aquatic invertebrates and fish due to bioaccumulation in their tissues. ${ }^{7,8}$ It is also toxic to honey bees, ${ }^{\mathbf{9}, 10}$ non-targeted insects and earthworms up to two weeks after it is supplied to soil. ${ }^{11}$ Thus, the selective and sensitive detection of chlorpyrifos is very necessary. Soluble sulfides generally coexist in the state of sulfide ion $\left(\mathrm{S}^{-}\right)$or hydrogen sulfide $\left(\mathrm{HS}^{-}\right)$, which are corrosive in nature. ${ }^{12}$ Various methods have been developed for the determination of chlorpyrifos, such as electrochemical methods for the determination of chlorpyrifos on a nano- $\mathrm{TiO}_{2} /$ cellulose acetate composite-modified glassy carbon electrode. ${ }^{\mathbf{1 3}}$ Gold nanoparticles have been applied for the detection of chlorpyrifos in various water samples. ${ }^{\mathbf{1 4}}$ Chlorpyrifos attached 
to quantum dots shows changes in fluorescence intensity as sensed through flow cytometry. ${ }^{15}$ Surface-enhanced Raman spectroscopy was used for the detection of chlorpyrifos in spinach with silver colloids. ${ }^{16}$ A silver nanohexagon solution is used for the sensing of chlorpyrifos via UV-Vis absorption spectroscopy. ${ }^{17}$ These methods are sensitive and specific; however, they involve complex sample preparation, are timeconsuming and expensive, and require sophisticated instruments, which limit their further applications. Colorimetric methods are more applicable due to their direct, rapid and simple process of detection. Changes in colour can be observed with naked eye; it does not require expensive or sophisticated instrumentation and can be applied directly in the field.

Recently, several studies have been reported on the colorimetric detection of other biomolecules and toxic ions by exploiting the oxidase-mimicking property. For instance, researchers have used the oxidase-like property of gold nanoclusters for the quantification of melamine in raw milk and milk powder. ${ }^{18}$ Li et al. synthesized a cobalt and nitrogen co-doped hierarchically porous carbon hybrid with oxidase mimicking properties for the colorimetric detection of glutathione. ${ }^{19} \mathrm{Ag}-\mathrm{CoFe}_{2} \mathrm{O}_{4} /$ reduced graphene oxide nanocomposites were engineered for the detection of $\mathrm{Hg}^{2+}{ }^{20}$ Researchers found oxidase-like activities in cobalt oxyhydroxide $(\mathrm{CoOOH})$ nanoflakes, which oxidise colourless $o$-phenylenediamine (OPD) to yellow oxidized OPD to sense ascorbic acid. ${ }^{20}$ Verneker et al. developed an efficient synthesis of $\mathrm{MnFe}_{2} \mathrm{O}_{4}$ via a co-precipitation method with controlled morphology; it showed remarkable oxidase mimetic properties. ${ }^{21}$ Graphene quantum dot$\mathrm{Ag}$ nanoparticles show high oxidase and antibacterial properties for Gram-negative, Gram-positive and drug-resistant bacteria. ${ }^{22}$ Cerium oxide was also studied for $\mathrm{pH}$-tuneable oxidase activity for cancer folate biomarker sensors. ${ }^{23}$ Singh et al. also studied cerium molybdate-incorporated graphene oxide nanocomposites for glucose sensing. ${ }^{24}$ Researchers also found both peroxidase and oxidase-like activities for AuPt alloy NPs using TMB as a chromogenic material. ${ }^{25}$ Rope-like Co-Fe layered hydroxide nanosheets based on hierarchical structures were studied for intrinsic oxidasecatalytic activity. ${ }^{26}$ Citrate-capped silver nanoparticles exhibit oxidase activity to detect the concentration of mercury ions (II). ${ }^{27}$ Other researchers synthesized $\mathrm{Ag} @ \mathrm{Ag}_{3} \mathrm{PO}_{4}$ microcubes as oxidase mimics for the ultrasensitive detection of $\mathrm{Hg}^{2+} \cdot{ }^{28}$

Previous reports show the use of expensive noble metalbased colorimetric sensors based on platinum, rubidium, and gold in their colorimetric sensing systems. All these catalysts are expensive, less stable and not easily available. To overcome these issues, we have designed an efficient $\mathrm{Ag}_{3} \mathrm{PO}_{4} \mathrm{NP}$-based catalyst due to its high oxidizing properties and comparatively low cost. For a long time, $\mathrm{Ag}_{3} \mathrm{PO}_{4}$ NPs have been considered to have antibacterial properties against Staphylococcus aureus, Pseudomonas aeruginosa and Escherichia coli. ${ }^{29}$ Also, it is popularly preferred as a light-sensitive material as it shows excellent photo-oxidative properties for oxygen evolution and photocatalytic dye degradation under visible light irradiation because of its narrow band gap. ${ }^{30}$ Due to these advanced properties of $\mathrm{Ag}_{3} \mathrm{PO}_{4} \mathrm{NPs}$, we were interested to use them for the first time in colorimetric sensors for detection of chlorpyrifos. Many oxidase-mimetic nanomaterial sensors have already proliferated as colorimetric tools with high catalytic properties; however, here, the $\mathrm{Ag}_{3} \mathrm{PO}_{4}$ NPs oxidize TMB in one step with high sensitivity. Therefore, the wide range of practical applications of $\mathrm{Ag}_{3} \mathrm{PO}_{4}$ NPs and their high oxidative properties may offer more importance in the field of sensing.

\section{Materials and methods}

\subsection{Chemicals and reagents}

All chemicals and reagents were used in the entire experiment without further purification. Silver nitrate, di-sodium hydrogen phosphate, 3,3' ,5, $5^{\prime}$-tetramethylbenzene (TMB), DMSO, sodium acetate, glacial acetic acid, chlorpyrifos, Endosulfan, Fenson, Carbofuran, Aldrin, Dieldrin and Benfuracarb were bought from Sigma-Aldrich India and were used without further purification. Milli-Q water was prepared by an integral water purification system (EMD Millipore).

\subsection{Synthesis of $\mathrm{Ag}_{3} \mathrm{PO}_{4} \mathrm{NPs}$}

A simple co-precipitation method was used for the synthesis of $\mathrm{Ag}_{3} \mathrm{PO}_{4} \mathrm{NPs}^{30} 60 \mathrm{mM}(50 \mathrm{~mL})$ silver nitrate added to Milli-Q water was magnetically stirred at $500 \mathrm{rpm}$ for $15 \mathrm{~min}$ in the dark to obtain a transparent solution containing silver and nitrate ions. $20 \mathrm{mM}(50 \mathrm{~mL}) \mathrm{Na}_{2} \mathrm{HPO}_{4}$ in Milli-Q water was separately stirred for $15 \mathrm{~min}$ to obtain a transparent solution containing sodium and phosphate ions. This solution was added dropwise in a continuous manner to the prepared silver nitrate solution, which was then stirred for another $6 \mathrm{~h}$. The obtained lemon yellow precipitate was centrifuged, washed multiple times with Milli-Q water, ethanol and dried at $60^{\circ} \mathrm{C}(12$ h) in the dark. The powdered $\mathrm{Ag}_{3} \mathrm{PO}_{4}$ NPs were stored in the dark for further analysis. A schematic of the mechanism of the $\mathrm{Ag}_{3} \mathrm{PO}_{4}$ NPs synthesis is shown in Scheme 1.

\subsection{Steady state kinetic assay for the oxidase-like activity of $\mathrm{Ag}_{3} \mathrm{PO}_{4} \mathrm{NPs}$}

The oxidase-like activity of the $\mathrm{Ag}_{3} \mathrm{PO}_{4}$ NPs was confirmed by using TMB substrate as a chromogenic material. TMB is converted to the oxidised TMB (oxTMB) blue colour complex in the presence of oxidizing agents such as free radicals of $\mathrm{H}_{2} \mathrm{O}_{2}$, direct sunlight exposure, horseradish peroxidase (HRP) and oxidizing enzymes or nanozymes. The $\mathrm{Ag}_{3} \mathrm{PO}_{4}$ NPs directly oxidize TMB to oxTMB (blue colour) in a one-step process. These nanoparticles act as oxidase nanozymes in the replacement of conventional HRP. Different concentrations of TMB (0.05-0.5 mM) were prepared in DMSO at room temperature. To optimize the reaction system, $60 \mu \mathrm{L}\left(0.8 \mathrm{mg} \mathrm{mL}^{-1}\right) \mathrm{Ag}_{3} \mathrm{PO}_{4}$ NPs were incubated with TMB in $2.0 \mathrm{~mL}$ sodium acetate buffer $(\mathrm{pH} 4.8)$. The blue oxTMB was analyzed using a UV/Visible spectrophotometer with the maximum absorbance at $652 \mathrm{~nm}$. The obtained data were fitted with the Michaelis-Menten equation and Lineweaver-Burk equation, as given below:

$$
V_{\mathrm{o}}=\frac{V_{\max }[S]}{K_{\mathrm{m}}+[S]} \& \frac{1}{V_{0}} \frac{K_{\mathrm{m}}}{V_{\max }}\left(\frac{1}{[S]}+\frac{1}{K_{\mathrm{m}}}\right)
$$




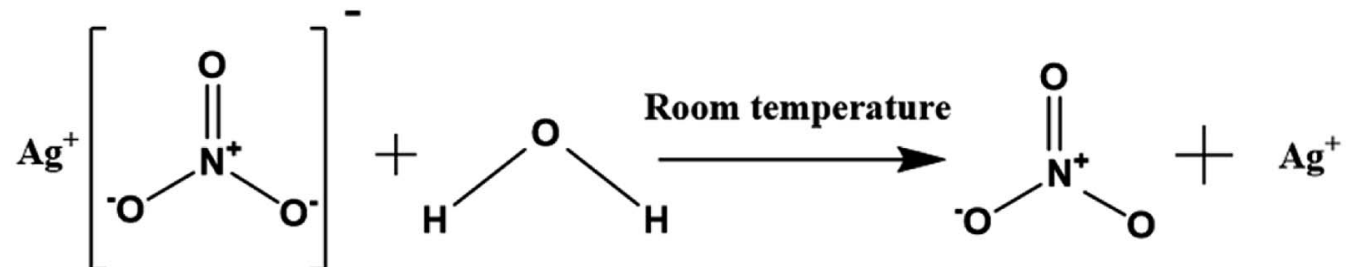<smiles></smiles>

Water

Nitrate

Silver ion

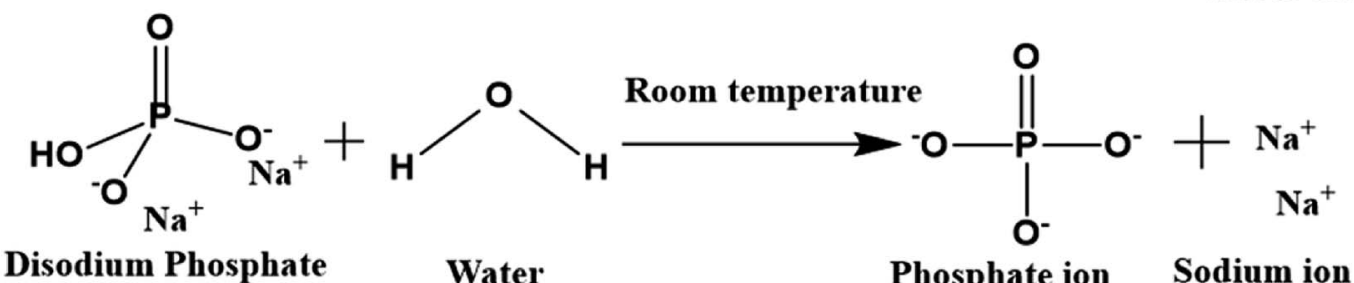
Disodium Phosphate

Water

Phosphate ion Sodium ion

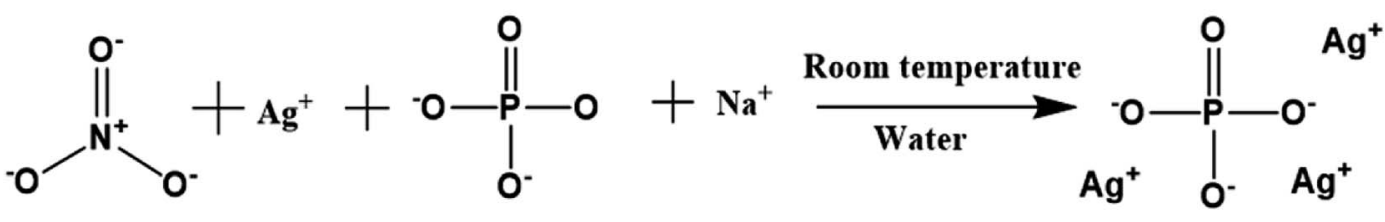

\section{Nitrate Silver ion Phosphate ion Sodium ion}

Silver Phosphate

Scheme 1 Schematic of silver phosphate nanoparticles synthesized by a simple co-precipitation route.

where $V_{0}$ is the initial velocity of interaction of the $\mathrm{Ag}_{3} \mathrm{PO}_{4}$ nanozymes with the substrate TMB, $V_{\max }$ is the maximal velocity of the proposed reaction, $[S]$ is the TMB substrate concentration and $K_{\mathrm{m}}$ is the Michaelis-Menten constant.

\subsection{Robustness with respect to reusability, $\mathrm{pH}$, temperature and time}

For reusability analysis, $80 \mathrm{~mL}(4.8 \mathrm{pH})$ acetate buffer, $2.4 \mathrm{~mL}$ $\left(0.8 \mathrm{mg} \mathrm{mL}{ }^{-1}\right) \mathrm{Ag}_{3} \mathrm{PO}_{4}$ NPs and $4 \mathrm{~mL}(0.5 \mathrm{mM})$ TMB were mixed and incubated for $180 \mathrm{~s}$ before spectrophotometric analysis. For the next cycle, the sample was centrifuged at $16000 \mathrm{rpm}$ at $4{ }^{\circ} \mathrm{C}$ and re-dispersed in $2.4 \mathrm{~mL}$ Milli-Q water; then, we followed the same experiment described above. This process was continued
Table 1 FTIR band positions of the $\mathrm{Ag}_{3} \mathrm{PO}_{4} \mathrm{NPs}$

\begin{tabular}{llll} 
S. no. & $\begin{array}{l}\text { Band position } \\
\left(\mathrm{cm}^{-1}\right)\end{array}$ & $\begin{array}{l}\text { Functional group vibration/bending } \\
\text { modes }\end{array}$ & Reference \\
\hline 1 & 3223 & O-H stretching & 31 \\
2 & 1659 & H-O-H bending & 31 \\
3 & 994 & P-O stretching & 32 \\
4 & 548 & O=P-O bending & 32
\end{tabular}

for six repeated cycles. For pH-based robustness, $50 \mathrm{mg}$ of $\mathrm{Ag}_{3} \mathrm{PO}_{4} \mathrm{NPs}$ were incubated in each reaction system ( $\mathrm{pH} \mathrm{2-12)}$ for $1 \mathrm{~h}$. After incubation, the $\mathrm{Ag}_{3} \mathrm{PO}_{4} \mathrm{NPs}$ were centrifuged,
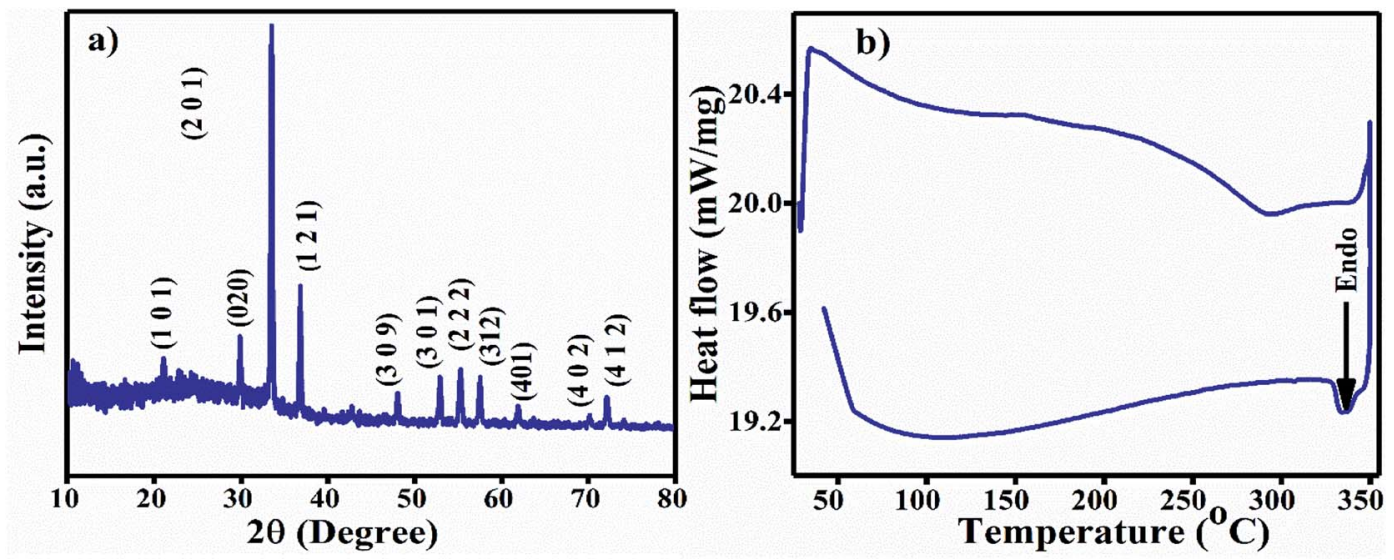

Fig. 1 (a) XRD diffraction pattern of the $\mathrm{Ag}_{3} \mathrm{PO}_{4} \mathrm{NPs}$. (b) DSC curve of the $\mathrm{Ag}_{3} \mathrm{PO}_{4}$ NPs. 

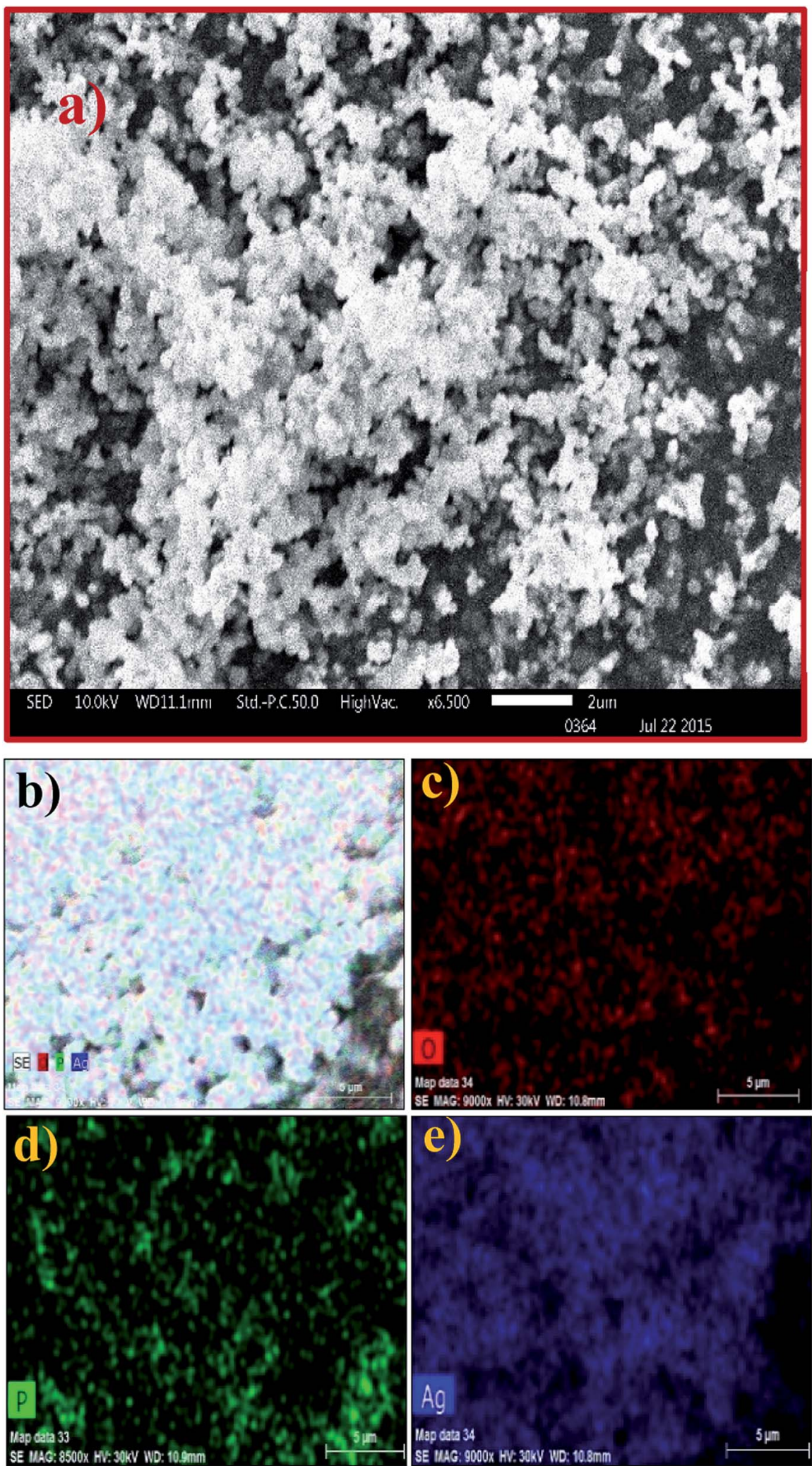

Fig. 2 (a) SEM image and (b-e) elemental mapping of the $\mathrm{Ag}_{3} \mathrm{PO}_{4} \mathrm{NPs}$.

washed, dried, and subjected to the same sensing method under the pre-optimized conditions described above. For temperature-based stability studies, the NPs were placed in different temperatures $\left(20-80{ }^{\circ} \mathrm{C}\right)$ for $1 \mathrm{~h}$, and the same experiment was performed. For long-term stability studies, the oxidase-mimicking activity of the $\mathrm{Ag}_{3} \mathrm{PO}_{4}$ NPs was checked by 
recording the absorbance of oxTMB at $652 \mathrm{~nm}$ every alternate day up to 26 days.

\subsection{Colorimetric detection of chlorpyrifos pesticide}

For colorimetric detection, all glassware was thoroughly cleaned with Milli-Q water and aquaregia. 200 ppm of chlorpyrifos stock solution was prepared in DMSO and stored for further use. $2 \mathrm{~mL}$ volumes of acetate buffer ( $\mathrm{pH} 4.8)$ containing different concentrations of chlorpyrifos (20-200 ppm) were prepared by maintaining the volume. $60 \mu \mathrm{L}\left(0.8 \mathrm{mg} \mathrm{mL} \mathrm{m}^{-1}\right)$ of $\mathrm{Ag}_{3} \mathrm{PO}_{4}$ NPs was added to all the glass vials; then, $100 \mu \mathrm{L}$ of $0.5 \mathrm{mM}$ TMB solution was agitated at room temperature. The obtained blue solution of oxTMB was analyzed by spectrophotometry.

\subsection{Selectivity analysis}

For selectivity analysis, seven different reaction systems were designed using 200 ppm of seven different pesticides (Benfuracarb, Endosulfan, Fenson, Carbofuran, Aldrin, Dieldrin and Chlorpyrifos) prepared in acetate buffer at pH 4.8. $60 \mu \mathrm{L}(0.8 \mathrm{mg}$ $\left.\mathrm{mL}^{-1}\right) \mathrm{Ag}_{3} \mathrm{PO}_{4}$ NPs were added to each solution of pesticides and incubated for $180 \mathrm{~s}$. Further, $0.1 \mathrm{~mL}(0.5 \mathrm{mM})$ of TMB solution was distributed in each of the seven reaction systems to check the blue colour of oxTMB.

\subsection{Real sample analysis}

Soil samples were collected from two different agriculture sites (Pethapur Village and Chiloda Village), Gandhinagar, Gujarat. Large particles, roots, etc. were separated from the soil samples, and the samples were dried (38-40 ${ }^{\circ} \mathrm{C}$ overnight), minced properly and filtered with clean cotton cloth to obtain homogeneous soil samples. The soil samples collected from Pethapur Village and Chiloda Village were labelled as S1 and S2, respectively. $10 \mathrm{~g}$ of each soil sample was agitated, washed at room temperature with $40 \mathrm{~mL}$ Milli-Q water, and filtered (Whatman No. 2 filter paper). The same process was repeated with hot $\left(75-80^{\circ} \mathrm{C}\right) 40 \mathrm{~mL}$ Milli-Q water in continuation, and the settled soil was collected for drying. This washed and dried sample was washed again with $40 \mathrm{~mL}$ of DMSO; finally, the filtrate was collected and termed as S1L or S2L. Further, the standard addition method was employed for the colorimetric detection of chlorpyrifos by the $\mathrm{Ag}_{3} \mathrm{PO}_{4}$ NPs catalyst.
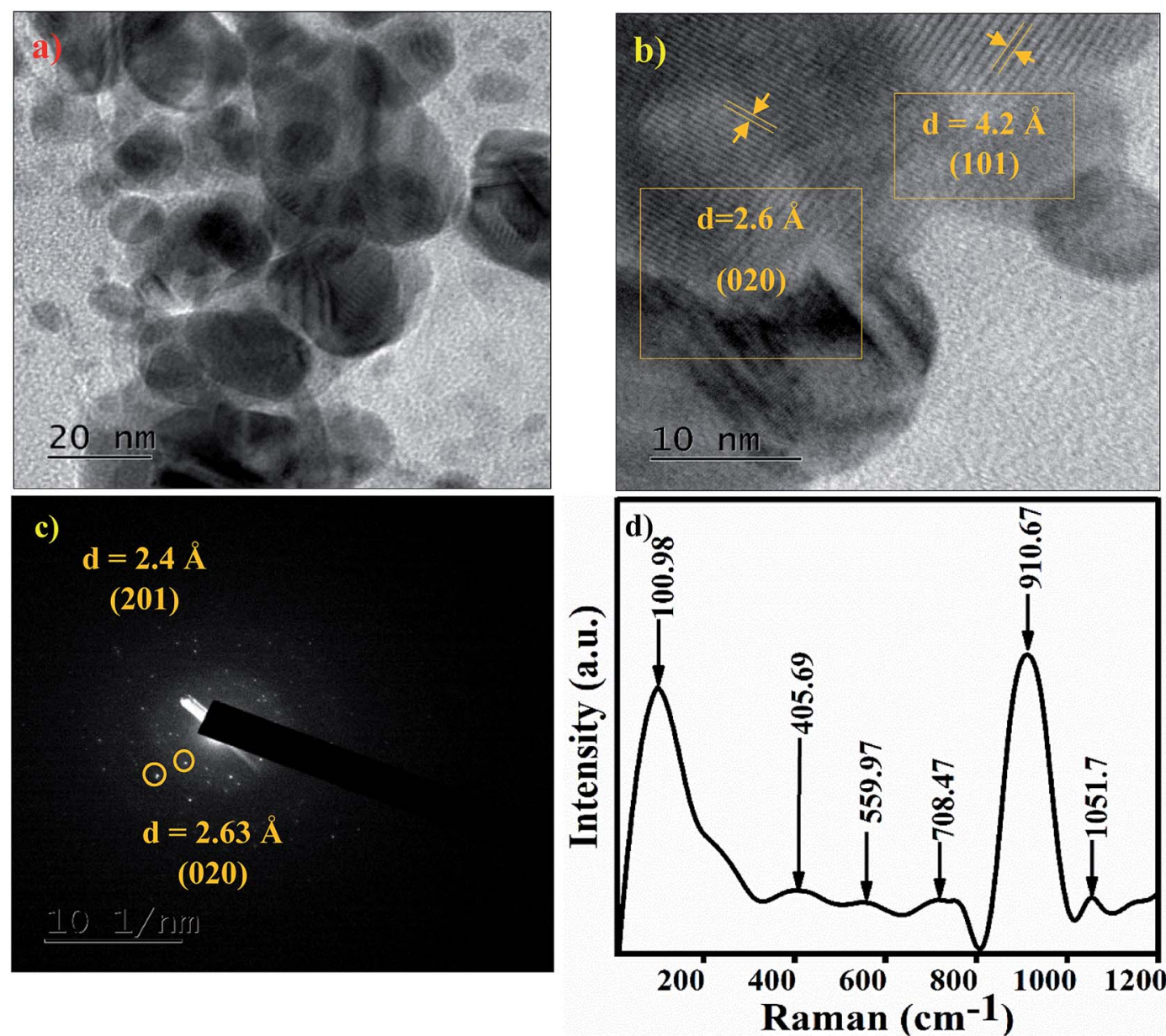

Fig. 3 (a) TEM image of the $\mathrm{Ag}_{3} \mathrm{PO}_{4} \mathrm{NPs}$. (b) HRTEM image of the $\mathrm{Ag}_{3} \mathrm{PO}_{4} \mathrm{NPs}$. (c) Electron diffraction pattern of the $\mathrm{Ag}_{3} \mathrm{PO} \mathrm{O}_{4} \mathrm{NPs}$ indexed with the (101) and (020) planes. (d) Raman spectra of the $\mathrm{Ag}_{3} \mathrm{PO}_{4} \mathrm{NPs}$. 


\subsection{Thermocol imprint method}

A $4 \times 2(l \times b) \mathrm{cm}^{2}$ rectangle of thermocol was imprinted with two alphabetic letters "A" beside each other. The imprinted letters were filled with $1 \mathrm{mg} \mathrm{mL}{ }^{-1} \mathrm{Ag}_{3} \mathrm{PO}_{4} \mathrm{NPs}$; then, the catalyst was maintained inside the imprint overnight and stored as a kit for further use. The thermocol imprint was filled with $4.8 \mathrm{pH}$ acetate buffer, chlorpyrifos and $0.5 \mathrm{mM}$ TMB solution, whereas the other imprint was filled only with acetate buffer and $0.5 \mathrm{mM}$ TMB solution. After $3 \mathrm{~min}$, blue colour was observed in the absence of chlorpyrifos, and no colour was observed in the imprint to which chlorpyrifos was added.

\section{Characterization}

Powder X-ray diffraction (PXRD) patterns were recorded using a Panalytical X Pert Pro $(\mathrm{Cu} \mathrm{K} \alpha, \lambda=1.5406 \AA$ A, $40 \mathrm{~mA}, 40 \mathrm{kV})$ with a step size of 0.03 at the rate of 0.6 per second. The crystallite sizes of the nanoparticles were calculated using the Scherrer equation:

$$
\tau=\frac{K \lambda}{\beta \cos \theta}
$$

where $\tau$ is the crystallite size, $K$ is the shape factor, and $\lambda$ is the $\mathrm{X}$ ray wavelength. $\beta$ is the corrected line broadening at half maximum intensity, and $\theta$ is the Bragg angle at the peak position. The UV-Vis absorbance was measured with a Shimadzu UV-1800. Fourier transform infrared spectra were recorded with a PerkinElmer Spectrum 65 instrument. A field emission scanning electron microscope (FE-SEM, Quanta 200 FEG) was used for the morphological analysis. A transmission electron microscope (TEM, Tecnai F20) was employed for the particle size analysis. Differential scanning calorimetry (DSC 6000, PerkinElmer) was used for the thermal stability-based exothermic and endothermic processes. FT-Raman spectroscopy (multi RAM, standalone model) was used to determine the structural and vibrational properties in the $4000-50 \mathrm{~cm}^{-1}$ range with a ND: YAG laser source of $1064 \mathrm{~nm}$. XPS (ESCA, Omnicorn Germany) was performed to determine the surface properties of the $\mathrm{Ag}_{3} \mathrm{PO}_{4}$ NPs.

\section{Results and discussion}

The XRD pattern of the $\mathrm{Ag}_{3} \mathrm{PO}_{4}$ NPs is shown in Fig. 1(a). All the diffraction peaks show $h k l$ values of (101), (020), (201), (121), (309), (301), (222), (312), (401), (402) and (412), corresponding to
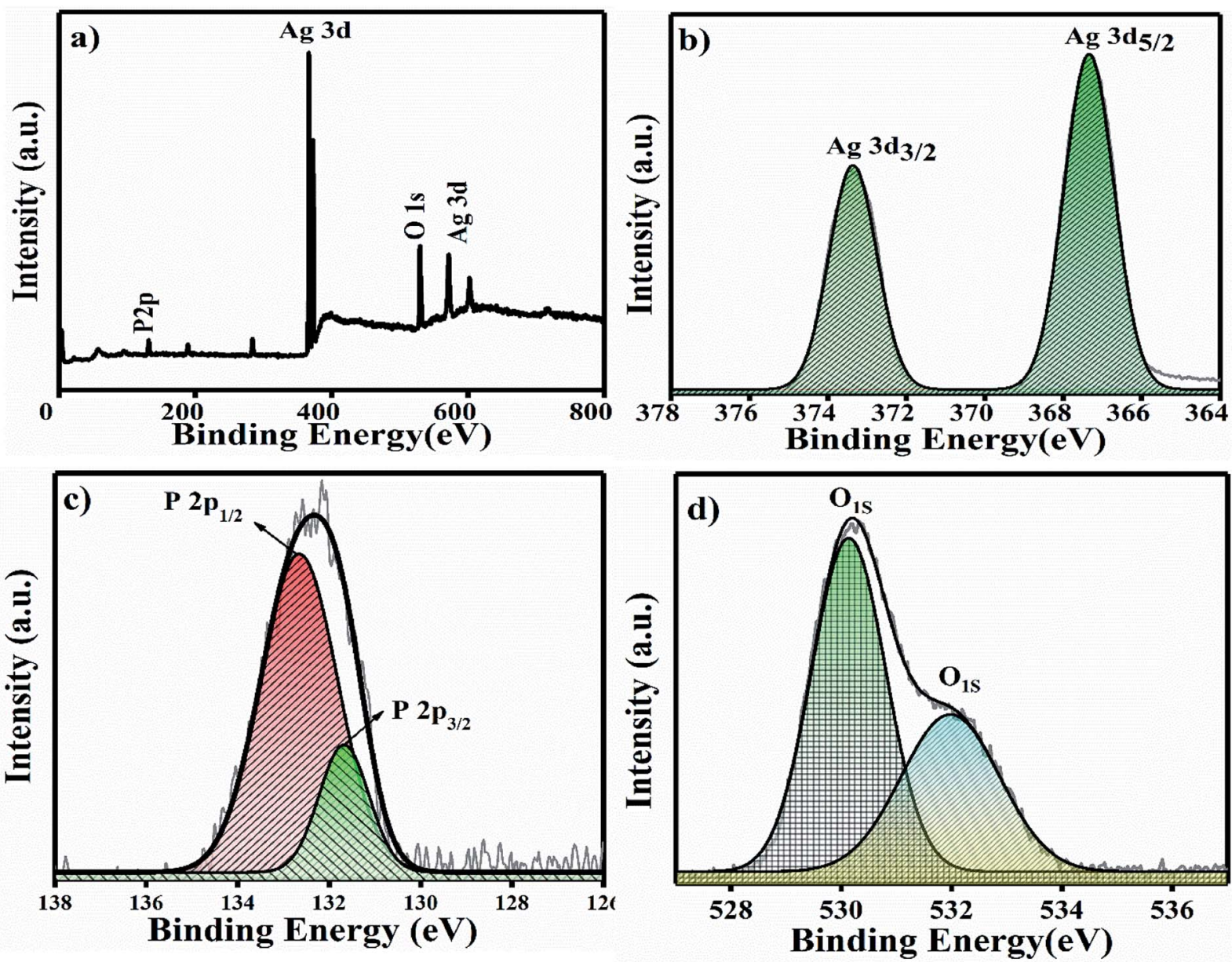

Fig. 4 (a) XPS full survey spectra of $\mathrm{Ag}_{3} \mathrm{PO}_{4} \mathrm{NPs}$ and (b-d) high resolution spectra of the $\mathrm{Ag} 3 \mathrm{~d}, \mathrm{P} 2 \mathrm{p}$ and $\mathrm{O}$ 1s spin orbit core levels. 
the $2 \theta$ values $21.08,29.91,33.54,36.42,48.02,52.94,55.27$, $57.48,61.90,70.12$ and 72.09 , which can be indexed to the cubic phase of $\mathrm{Ag}_{3} \mathrm{PO}_{4}$. The calculated crystallite size using Scherrer's formula $\tau=k \lambda / \beta \cos \theta$ is $\sim 2.8 \mathrm{~nm} .{ }^{30} \mathrm{UV}$-Vis spectroscopy was performed in the wavelength range of 200 to $800 \mathrm{~nm}$ using MilliQ water as the solvent. A broad hump was observed in the visible range, and 3 absorption peaks at $214 \mathrm{~nm}, 230 \mathrm{~nm}\left(\pi-\pi^{*}\right)$ and $275 \mathrm{~nm}\left(n-\pi^{*}\right)$ near the UV light absorption range can be observed in Fig. S1a. $\dagger$

For the FT-IR analysis, $\sim 2 \mathrm{mg} \mathrm{Ag}_{3} \mathrm{PO}_{4}$ NPs was mixed with $200 \mathrm{mg}$ moistureless $\mathrm{KBr}$, ground well and pressed with a hydraulic press to prepare a pellet. First, the $\mathrm{KBr}$ pellet was used for the background; then, the sample was analyzed in the range of $4000-400 \mathrm{~cm}^{-1}$ (Fig. $\mathrm{S} 1 \mathrm{~b} \dagger$ ). The two broad peaks originating at $\sim 3223 \mathrm{~cm}^{-1}$ and $1659 \mathrm{~cm}^{-1}$ are attributed to the $\mathrm{O}-\mathrm{H}$ stretching vibration and bending vibration of $\mathrm{H}-\mathrm{O}-\mathrm{H}$ in residual water molecules. ${ }^{31}$ A strong transmittance band as observed at $994 \mathrm{~cm}^{-1}$ due to the $\mathrm{P}-\mathrm{O}$ stretching vibrations of phosphate $\left(\mathrm{PO}_{4}{ }^{3-}\right)$. The vibration at $548 \mathrm{~cm}^{-1}$ is due to $\mathrm{O}=\mathrm{P}-\mathrm{O}$ group bending vibrations. ${ }^{32}$ All the FT-IR vibration bands are tabulated in Table 1 . The differential scanning calorimetric
(DSC) curve shows the existence of a small endothermic peak at $334{ }^{\circ} \mathrm{C}$, which may be due to decomposition of the $\mathrm{Ag}_{3} \mathrm{PO}_{4} \mathrm{NPs}$, as shown in Fig. $1 \mathrm{~b}$.

The SEM image of the $\mathrm{Ag}_{3} \mathrm{PO}_{4}$ NPs shows aggregated spherical particles with a size range of $\sim 100$ to $200 \mathrm{~nm}$, as shown in Fig. 2a. SEM elemental mapping micrographs clearly show the presence of $\mathrm{O}, \mathrm{P}$ and $\mathrm{Ag}$ without any impurities (Fig. 2b-e).

The TEM image of the $\mathrm{Ag}_{3} \mathrm{PO}_{4}$ NPs shows spherical particles in the range of 15-40 nm, as shown in Fig. 3(a). The high resolution TEM image of $\mathrm{Ag}_{3} \mathrm{PO}_{4}$ NPs shows the crystal planes (101) and (020), corresponding to the cubic phase of $\mathrm{Ag}_{3} \mathrm{PO}_{4}$ NPs (Fig. 3b). The electron diffraction pattern of the $\mathrm{Ag}_{3} \mathrm{PO}_{4}$ NPs in Fig. 3c shows a bright spot corresponding to the planes (201) and (020). The Raman spectrum of the $\mathrm{Ag}_{3} \mathrm{PO}_{4}$ NPs shows an inelastic, scattered intense peak at $\sim 910 \mathrm{~cm}^{-1}$, attributed to the terminal oxygen vibrational stretching of $\mathrm{PO}_{4}$ groups (Fig. 3d). The peak at $1051 \mathrm{~cm}^{-1}$ represents asymmetric stretching vibrations of $\mathrm{O}-\mathrm{P}-\mathrm{O}$ $\left[\mathrm{PO}_{4}\right]$, the peak at $\sim 708 \mathrm{~cm}^{-1}$ describes symmetric stretching of the $\mathrm{O}-\mathrm{P}-\mathrm{O}$ bond, the very weak peak at $\sim 559 \mathrm{~cm}^{-1}$ is associated with the asymmetric stretch of $\mathrm{P}-\mathrm{O}-\mathrm{P}$ vibrational bending, ${ }^{33}$ the
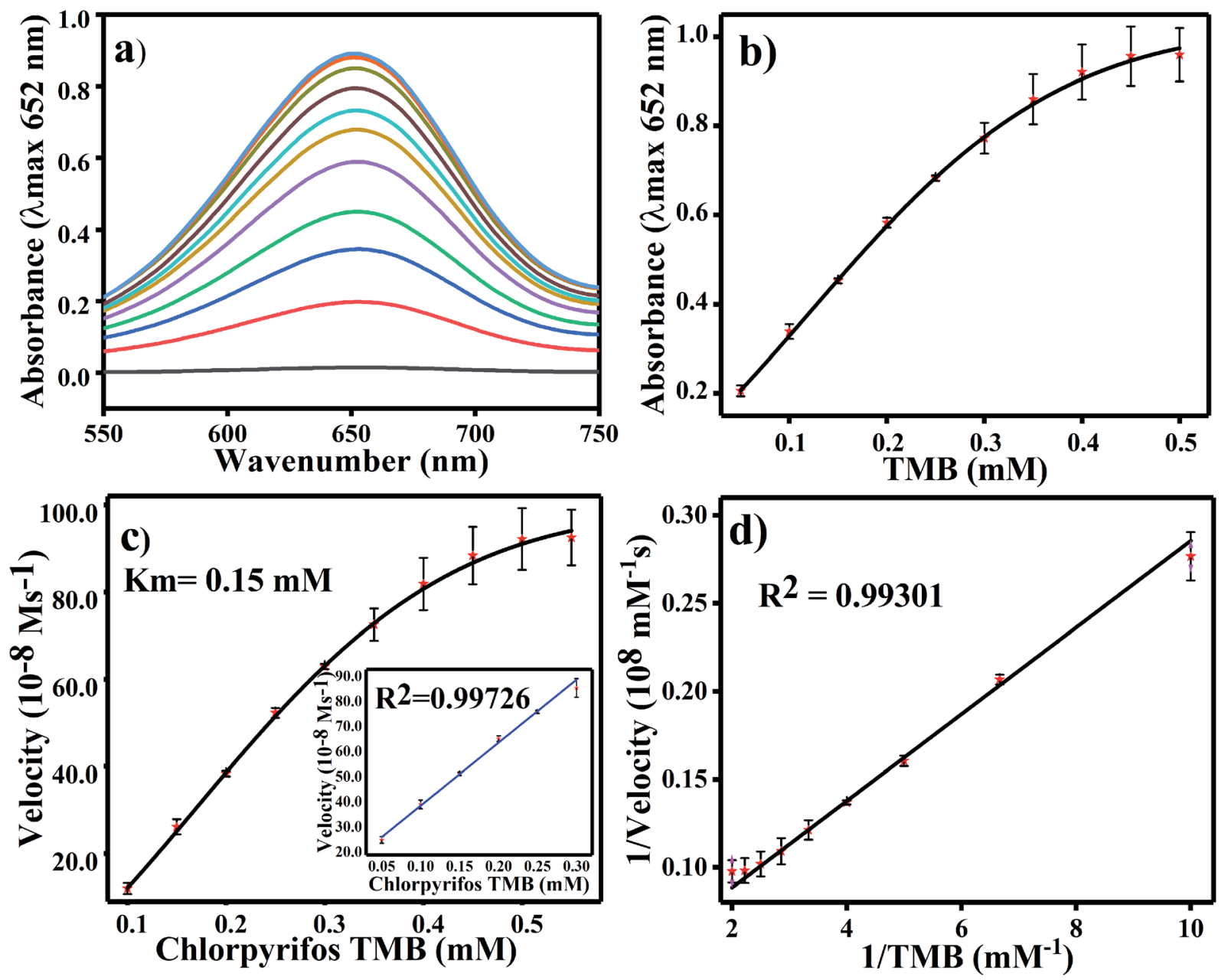

Fig. 5 (a) UV-Vis spectroscopy results for various TMB concentrations $(0.05-0.5 \mathrm{mM})$. (b) Linear absorbance graph of TMB at concentrations of 0.05 to $0.5 \mathrm{mM}$. (c) Kinetic assay analysis of the $\mathrm{Ag}_{3} \mathrm{PO}_{4} \mathrm{NPs}$ by Michaelis-Menten plot with the calculated $K_{\mathrm{m}}$ value and (d) Lineweaver-Burk plot of the $\mathrm{Ag}_{3} \mathrm{PO}_{4} \mathrm{NPs}$. 
peak at $\sim 405 \mathrm{~cm}^{-1}$ corresponds to symmetric bending vibration modes related to $\left[\mathrm{PO}_{4}\right]$ clusters, and the peak at $101 \mathrm{~cm}^{-1}$ is due to symmetric vibrational bending of $\mathrm{Ag}-\mathrm{O}$ bonds. ${ }^{34}$

The XPS full survey scan of $\mathrm{Ag}_{3} \mathrm{PO}_{4}$ is shown in Fig. 4a, in which the $\mathrm{P} 2 \mathrm{p}, \mathrm{Ag} 3 \mathrm{~d}$ and $\mathrm{O}$ 1s spin orbit core levels were detected. High-resolution XPS spectra of the P 2p, Ag 3d and O 1s spin orbit core levels are shown in Fig. $4 \mathrm{~b}-\mathrm{d}$. $\mathrm{Ag} 3 \mathrm{~d}$ has a core level spectrum with two binding energy peaks at $373.34 \mathrm{eV}$ and $367.35 \mathrm{eV}$ due to the electron orbitals of $\mathrm{Ag} 3 \mathrm{~d}_{3 / 2}$ and $\mathrm{Ag} 3 \mathrm{~d}_{5 / 2}$, consistent with the oxidation state of $\mathrm{Ag}^{+}$in $\mathrm{Ag}_{3} \mathrm{PO}_{4} \cdot{ }^{35}$ Fig. $4 \mathrm{c}$ shows the high resolution XPS spectra for the $\mathrm{P} 2 \mathrm{p}$ spin orbit core levels; the two binding energy peaks originating at 132.6 and $131.7 \mathrm{eV}$ correspond to the electron orbitals of $\mathrm{P} 2 \mathrm{p}_{1 / 2}$ and $\mathrm{P}$ $2 \mathrm{p}_{3 / 2}$, which supports that phosphorous is in the $\mathrm{P}^{+5}$ oxidation state in $\mathrm{Ag}_{3} \mathrm{PO}_{4} \cdot{ }^{36}$

\subsection{Optimization of TMB and steady state kinetic assay}

For TMB optimization, various concentrations of TMB $(0.05$ to $0.5 \mathrm{mM}$ ) were added to $2 \mathrm{~mL}$ of acetate buffer ( $\mathrm{pH} 4.8)$ containing $60 \mu \mathrm{L}$ of a $0.8 \mathrm{mg} \mathrm{mL}{ }^{-1}$ concentration of $\mathrm{Ag}_{3} \mathrm{PO}_{4}$. The UV/Vis results are shown in Fig. 5. As shown in Fig. 5a, as the concentration of TMB increases, the absorbance at 652 increases. The change in absorbance at $652 \mathrm{~nm}$ is shown in Fig. 5b, in which the graph plateaus at $\sim 0.5 \mathrm{mM}$. $0.5 \mathrm{mM}$ TMB concentration is considered to be the optimal concentration for further experiments. For the steady state kinetic assay, TMB was used as a substrate and chromogenic material. Using the absorption coefficient of TMB $\left(\varepsilon=39000 \mathrm{M}^{-1} \mathrm{~cm}^{-1}\right)$, a Michaelis-Menten plot was obtained for increasing concentrations of TMB (Fig. 5c). The inset of Fig. 5c shows the linear response of TMB oxidation at all optimal conditions. A double reciprocal or Lineweaver-Burk plot was obtained and is given in Fig. 5d. The Michaelis-Menten constant $\left(K_{\mathrm{m}}\right)$ was calculated from the Michaelis-Menten plot and was found to be $0.15 \mathrm{mM}$.

\subsection{Effects of $\mathrm{Ag}_{3} \mathrm{PO}_{4}$ concentration, incubation $\mathrm{pH}$, time and temperature}

For the optimization of the concentration of $\mathrm{Ag}_{3} \mathrm{PO}_{4} \mathrm{NPs}$, incubation $\mathrm{pH}$, time and temperature, the reaction system was incubated with different concentrations of $\mathrm{Ag}_{3} \mathrm{PO}_{4} \mathrm{NPS}$ (0.1$\left.1 \mathrm{mg} \mathrm{mL} \mathrm{mL}^{-1}\right), \mathrm{pH}$ values (3.6-5.6), times (0-4.0 min.) and temperatures $\left(20-55^{\circ} \mathrm{C}\right)$. Fig. 6 a shows the effects of NPs
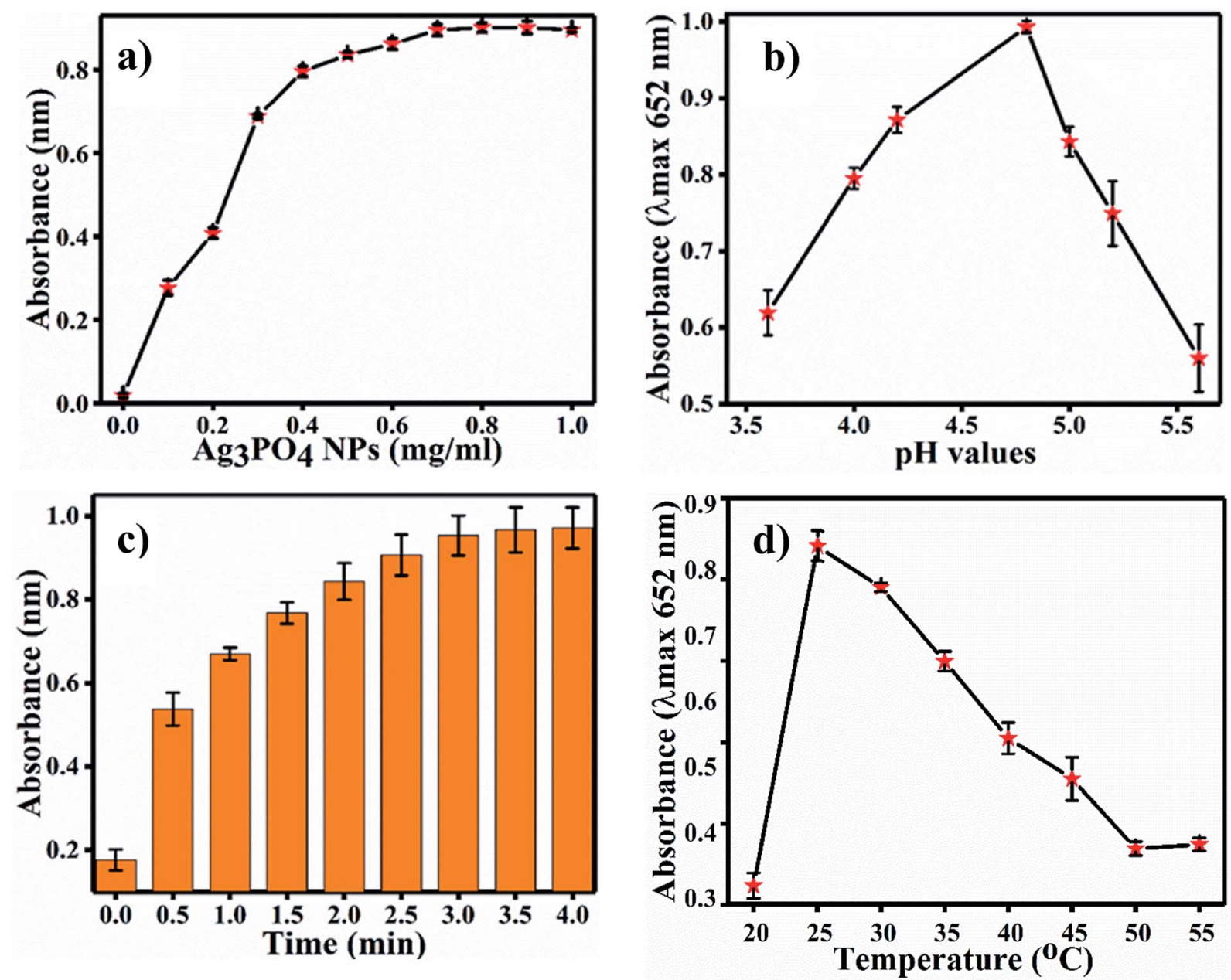

Fig. 6 (a) Changes in maximum absorbance with varying concentrations of $\mathrm{Ag}_{3} \mathrm{PO}_{4}$. (b) Calibration plot of $\mathrm{pH}$ (c), calibration plot of time in min and (d) calibration plot of temperature at $\lambda_{\max }=652 \mathrm{~nm}$ for further experiments. 
concentration on TMB oxidation. As the NPs concentration increases, the absorbance at 652 increases; the graph plateaus at $0.8 \mathrm{mg} \mathrm{mL} \mathrm{mL}^{-1}$ concentration, as shown in Fig. 6a. Hence, $0.8 \mathrm{mg} \mathrm{mL}{ }^{-1}$ concentration of $\mathrm{Ag}_{3} \mathrm{PO}_{4}$ was considered as the optimal concentration for further sensing applications. Fig. $6 \mathrm{~b}-\mathrm{d}$ show the effects of incubation $\mathrm{pH}$, time and temperature on TMB oxidation, respectively. The maximum absorbance at $652 \mathrm{~nm}$ of oxTMB was recorded at pH 4.8, 3 min and $25{ }^{\circ} \mathrm{C}$. Hence, these parameters were set as the optimal conditions for sensing.

\subsection{Mechanism of chlorpyrifos sensing}

As shown in Scheme 2, when the $\mathrm{Ag}_{3} \mathrm{PO}_{4}$ NPs come in proper orientation proximity with TMB, TMB acts as a substrate for the $\mathrm{Ag}_{3} \mathrm{PO}_{4}$ nanozyme. After oxidation, TMB shows a blue colour, which can be tuned to optimal parameters. ${ }^{37}$

Therefore, when chlorpyrifos pesticide comes in proximity with the $\mathrm{Ag}_{3} \mathrm{PO}_{4} \mathrm{NPs}$, it is oxidized to form chlorpyrifos oxon and sulfide ion, as shown in Scheme 2. These produced sulfide ions feedback to the $\mathrm{Ag}_{3} \mathrm{PO}_{4}$ NPs and block their activity. Similarly, W. Qin et al. synthesized $\mathrm{Co}_{3} \mathrm{O}_{4}$ NPs for the sensing of sulphite in food and inhibited their colour formation; ${ }^{38}$ also, R. Chen et al. created a hydrogen sulfide gas sensor in the presence of silver NPs film. ${ }^{39}$ The sulfide ion released in this reaction after the oxidation of chlorpyrifos is attached to the active site of the $\mathrm{Ag}_{3} \mathrm{PO}_{4}$ NPs, as shown in Scheme 2.

\subsection{Robustness}

Long-term durability of a nano-sensor is one of the most important aspects required for its satisfactory application. Indeed, the activity of colorimetric nano-sensors depends upon the colour signals generated without substrate and in the presence of the desired sensing materials. Thus, the deviation in colour intensity enables the quantification of the sensing material, and it should not deviate in response to common factors such as $\mathrm{pH}$, temperature and time; also, the reusability of nano-sensors is important. The recyclability of the $\mathrm{Ag}_{3} \mathrm{PO}_{4}$ NPs indicates the potential to reuse the same nanoparticles six times (Fig. 7a). A much less steep decrease in blue colour (oxTMB) was observed up to the sixth cycle. Other nanoparticles have also showed reusable properties, such as $\mathrm{Fe}^{3+}$-doped mesoporous carbon nanospheres. ${ }^{40}$ Samples were incubated at different $\mathrm{pH}$ values from 2 to 12 for $1 \mathrm{~h}$. The $\mathrm{Ag}_{3} \mathrm{PO}_{4}$ NPs show stability under different harsh $\mathrm{pH}$ conditions (Fig. 7b). The catalytic activity is almost constant, and there is no recordable decrease in activity. The temperature stability of the $\mathrm{Ag}_{3} \mathrm{PO}_{4} \mathrm{NPs}$ was also recorded in the range of $20-80{ }^{\circ} \mathrm{C}$; as shown in Fig. $7 \mathrm{c}$, no decrease in the reaction activity of the NPs was observed.<smiles>CCOP(=S)(OCC)Oc1nc(Cl)c(Cl)cc1Cl</smiles>

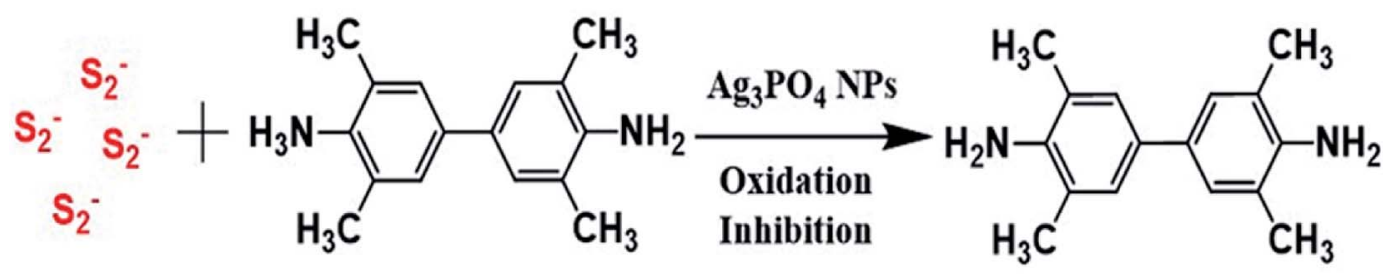

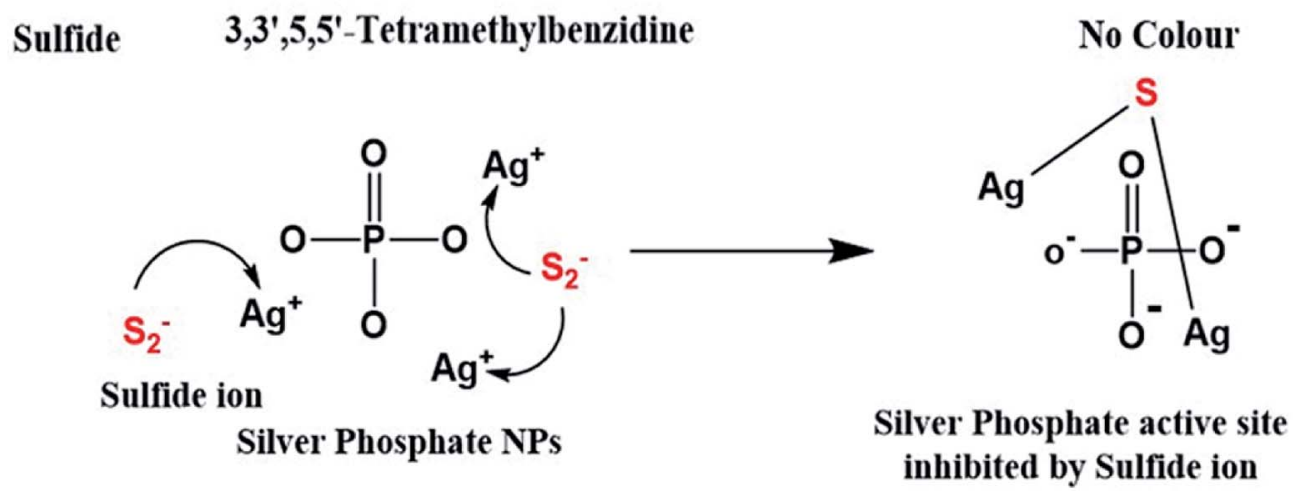

Scheme 2 Schematic of the catalytic action of silver phosphate NPs on chlorpyrifos. 
Similarly, the stability of the NPs was examined during storage from 2 to 26 days every alternative day (Fig. 7d). The storage time reaction stability was also found to be acceptable up to 26 days of continuous incubation. No considerable decrease in the catalytic activity of the NPs was observed. Thus, it can be concluded that the synthesized NPs are stable with respect to $\mathrm{pH}$, temperature, and storage time and can be reused up to six times.

\subsection{Colorimetric sensing of chlorpyrifos}

Colorimetric sensing of chlorpyrifos was studied using TMB, which is a chromogenic substrate for $\mathrm{Ag}_{3} \mathrm{PO}_{4}$ NPs. In the presence of $\mathrm{Ag}_{3} \mathrm{PO}_{4} \mathrm{NPs}$, increasing concentrations of chlorpyrifos decreased the intensity of the peak of the blue colour (oxTMB) (Fig. 8a). 200 ppm chlorpyrifos shows a less intense peak at $650 \mathrm{~nm}$. Further increasing the concentration of chlorpyrifos diminished the blue colour peak. Oxidized chlorpyrifos was converted into chlorpyrifos oxon and sulfide ion, as shown in Scheme 2. Thus, the $\mathrm{Ag}_{3} \mathrm{PO}_{4}$ NPs are confirmed to be oxidase mimetic nanozymes. In Scheme 2, one of the products, sulfide ion, interacts with the $\mathrm{Ag}_{3} \mathrm{PO}_{4} \mathrm{NPs}$; it inhibits the active sites and blocks the oxidizing activity to convert TMB to blue oxTMB as a negative feedback loop. The study of the reaction kinetics measured the reaction rate and affinity of the $\mathrm{Ag}_{3} \mathrm{PO}_{4}$ nanoenzymes towards TMB (substrate).

Sulfide ion sensing as a proof of concept experiment. We performed the $\mathrm{S}^{2-}$ ions sensing experiment in pre-optimized conditions as a proof of concept. For this experiment, we used $\mathrm{Na}_{2} \mathrm{~S}$ with different concentrations ( $0 \mathrm{ppm}$ to $200 \mathrm{ppm}$ ) in water and tested for $\mathrm{S}^{2-}$ ions in the reaction solution. Fig. 8e shows the UV/Vis. spectra with increasing concentrations of $\mathrm{S}^{2-}$ ions $\left(\mathrm{Na}_{2} \mathrm{~S}\right)$, and Fig. 8f shows the change in absorbance at $652 \mathrm{~nm}$. As the concentration of $\mathrm{S}^{2-}$ increases, the absorbance at $652 \mathrm{~nm}$ decreases gradually; this indicates that $\mathrm{S}^{2-}$ inhibits the oxidase mimicking activity of $\mathrm{Ag}_{3} \mathrm{PO}_{4}$. For the selectivity test, chlorpyrifos was tested with six other pesticides, namely Benfuracarb, Endosulfan, Fenson, Carbofuran, Aldrin and Dieldrin (their structures are shown in Fig. S2 $\dagger$ ). A total of seven reaction systems were developed to evaluate potential interference with the $\mathrm{Ag}_{3} \mathrm{PO}_{4}$ NPs in comparison to chlorpyrifos. In order to verify the feasibility of our approach for the detection of chlorpyrifos, the selectivity test results are shown in Fig. 9a and b. At $\lambda_{\max }=$ $652 \mathrm{~nm}$ for oxTMB, the various pesticides other than chlorpyrifos showed comparatively high colour intensity. The efficacy of the substrate for any enzyme can be estimated by measuring the
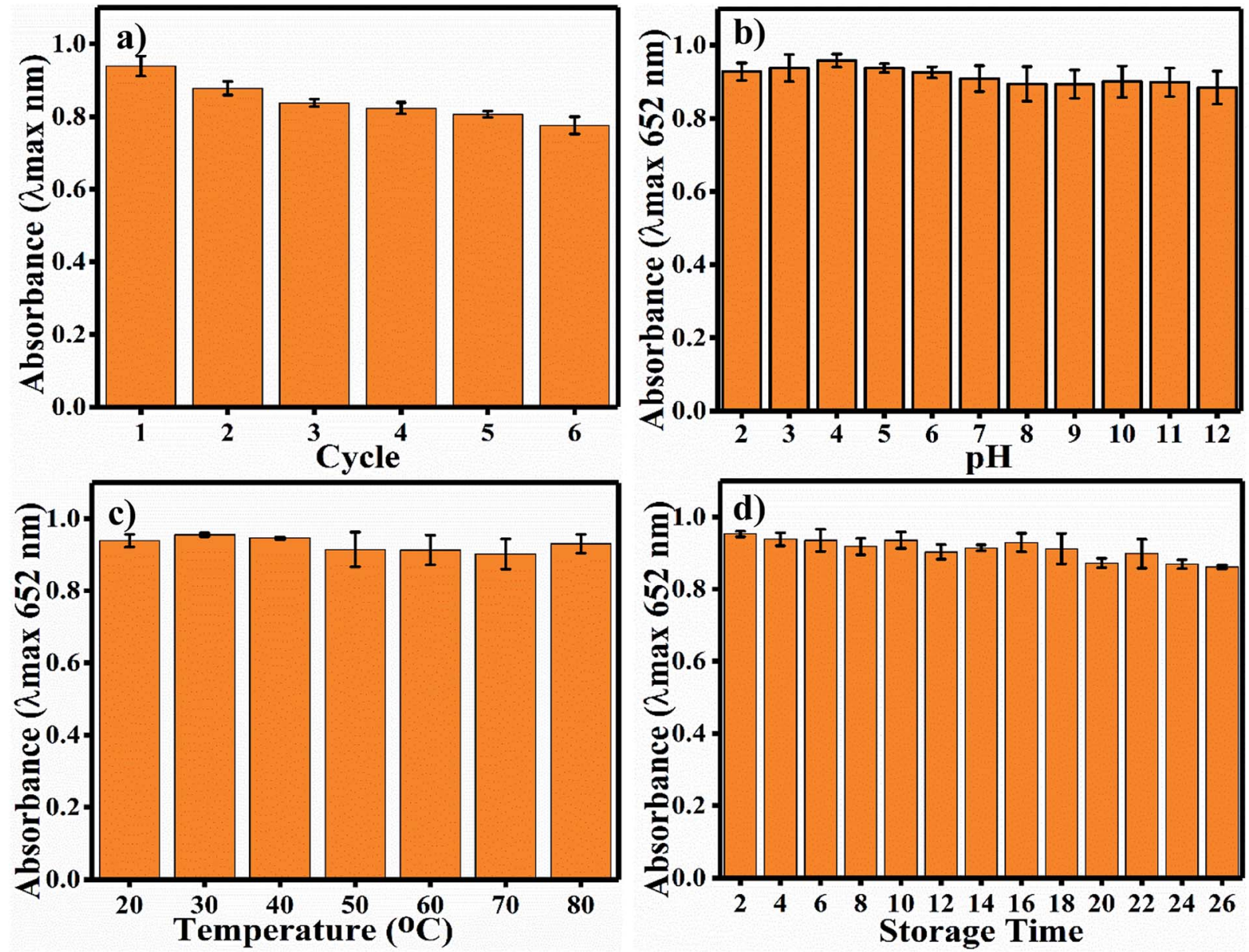

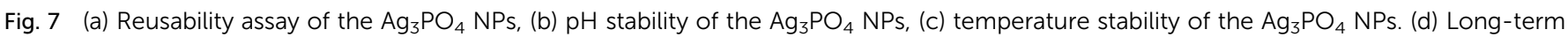
stability of the $\mathrm{Ag}_{3} \mathrm{PO}_{4} \mathrm{NPs}$ after storing the sample at room temperature. 
$K_{\mathrm{m}}$ value. Therefore, the $K_{\mathrm{m}}$ value of the $\mathrm{Ag}_{3} \mathrm{PO}_{4}$ NPs calculated for the TMB substrate is low, showing the higher proficiency of the reaction toward the TMB substrate.

The $K_{\mathrm{m}}$ value (Michaelis-Menten constant) represents the affinity of the catalytic efficiency of an enzyme for a substrate. Many researchers have developed oxidase mimetic nanoparticles, which are tabulated in Table 2 . In this table, we can see that the standard enzyme HRP is most traditionally involved in experiments of oxidation based on amperometric biosensors for polyphenol determination. ${ }^{41} \mathrm{HRP}$ is used as a glucose biosensor, as established through electro-enzyme catalyst oxidation of glucose $\mathrm{4}^{\mathbf{4}}$ and immobilizing HRP for oxidative polymerization of 2,6-dimethylphenol as a biocatalyst. ${ }^{43}$ Thus, from Table 2, the $K_{\mathrm{m}}$ value for HRP is about $0.434 \mathrm{mM}$, and the $K_{\mathrm{m}}$ value for the $\mathrm{Ag}_{3} \mathrm{PO}_{4}$ NPs is about $0.15 \mathrm{mM}$.

The developed analysis method, which is selective and sensitive for the standard chlorpyrifos, was applied for real sample analysis. Soil samples from Pethapur and Chiloda villages extracted in DMSO show absorbance at $652 \mathrm{~nm}$, as shown in Fig. 9(c) and (d), respectively. The gradient decreases (Fig. 9e) in the absorbance of the standard chlorpyrifos with increasing concentrations of Pethapur and Chiloda DMSO soil extracts, which indicates that chlorpyrifos was sensed (Fig. 9f). The resulting amounts found in the soil extracts, recovery percentages, and RSD values are tabulated in Table 3.
We analysed the $\mathrm{Ag}_{3} \mathrm{PO}_{4}$ catalyst after reacting it with TMB through XPS for Ag valence identification, and the XPS results are shown in Fig. 10. These results have also been added with the manuscript and highlighted with redcolour. According to the XPS results of $\mathrm{Ag}_{3} \mathrm{PO}_{4}$, the OKLL peak can be clearly observed on the surface, showing a higher concentration of oxygen due to exposure to ambient atmospheric conditions. The total scan spectrum binding energy range of $0-1100 \mathrm{eV}$ revealed that $\mathrm{Ag}, \mathrm{P}$ and $\mathrm{O}$ elements coexist in the $\mathrm{Ag}_{3} \mathrm{PO}_{4}$ nanoparticles. Noise peaks were observed after the reaction. In Fig. 10(a), a full survey scan shows the same number of elements which were present before the reaction. In Fig. 10(b), the three peaks positioned at $373.52 \mathrm{eV}, 368.00 \mathrm{eV}$ and $367.48 \mathrm{eV}$ in the high resolution spectrum of $\mathrm{Ag} 3 \mathrm{~d}$ can be assigned to the electron orbitals of $\mathrm{Ag} 3 \mathrm{~d}_{3 / 2}$ and $\mathrm{Ag} 3 \mathrm{~d}_{5 / 2}$ of $\mathrm{Ag}^{+}$, respectively. Thus, after the oxidation process of the $\mathrm{Ag}_{3} \mathrm{PO}_{4} \mathrm{NPs}$, no remarkable change is observed. Therefore, silver is only present in the $\mathrm{Ag}^{+}$state before and after the reaction. In Fig. 10(c), the peak with a binding energy of $132.51 \mathrm{eV}$ is ascribed to $\mathrm{P} 2 \mathrm{p}$ of $\mathrm{PO}_{4}{ }^{3-}$. The binding energy de-convoluted peaks at $530.31 \mathrm{eV}, 531.47 \mathrm{eV}$ and $532.85 \mathrm{eV}$ (Fig. 10d) were assigned to O $1 \mathrm{~s}$.

Reactive oxygen species (ROS) were investigated by introducing iso-propyl alcohol (IPA) as an $\mathrm{OH}^{*}$ scavenger and $p$ benzoquinone (BQ) as a superoxide radical $\left(\mathrm{O}_{2}^{--}\right)$scavenger. Fig. 11 shows the effects of the scavengers on the TMB oxidation process under all optimal conditions. Fig. 11a indicates the UV/
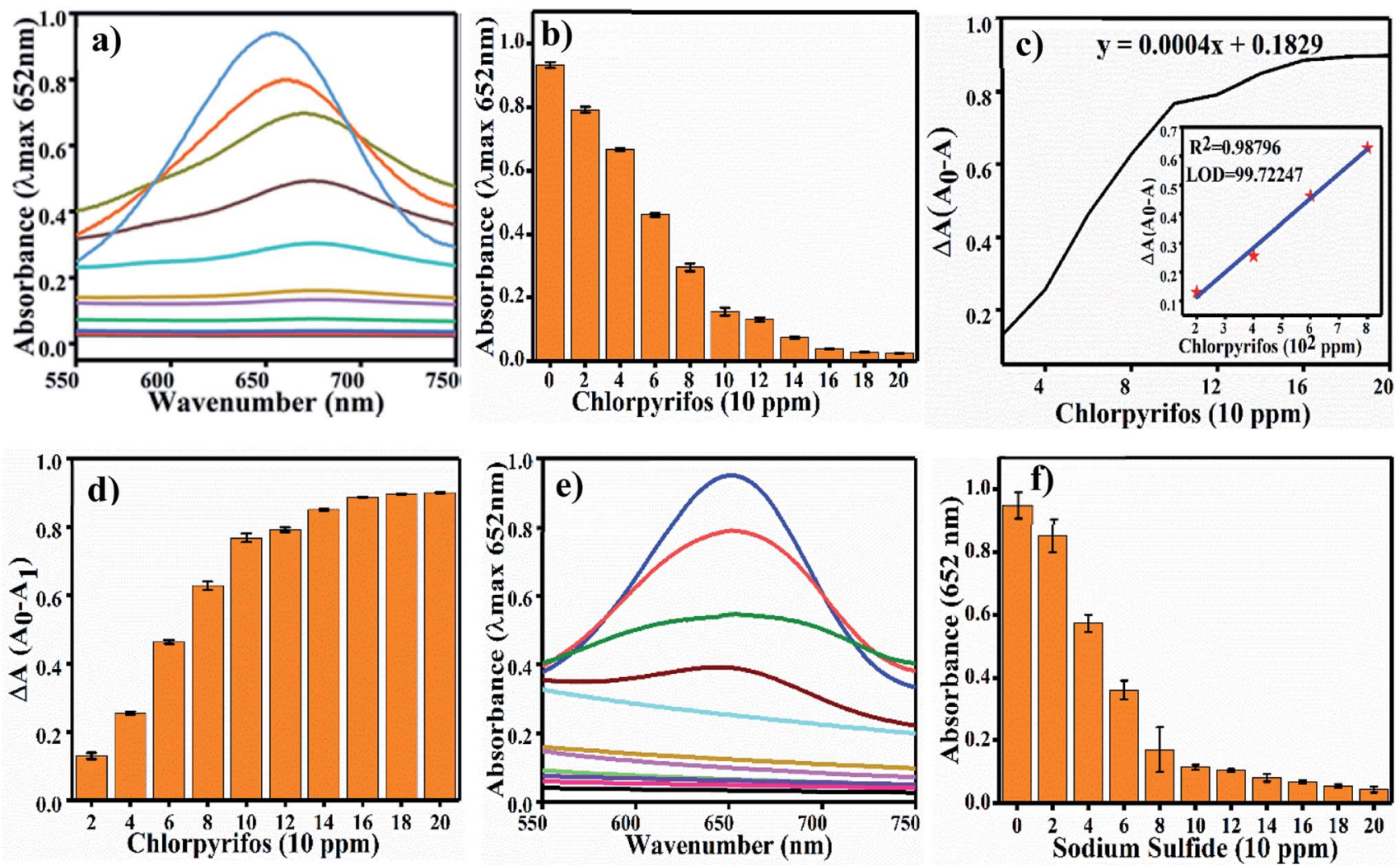

Fig. 8 (a) UV-Vis spectra of chlorpyrifos detection. (b) Different concentrations of chlorpyrifos absorbance at $652 \mathrm{~nm}$, (c) $\Delta A$ versus concentration graph and (d) $\Delta A$ of different concentrations of chlorpyrifos. (e and f) UV-Vis spectra and sulfide ion sensing. 

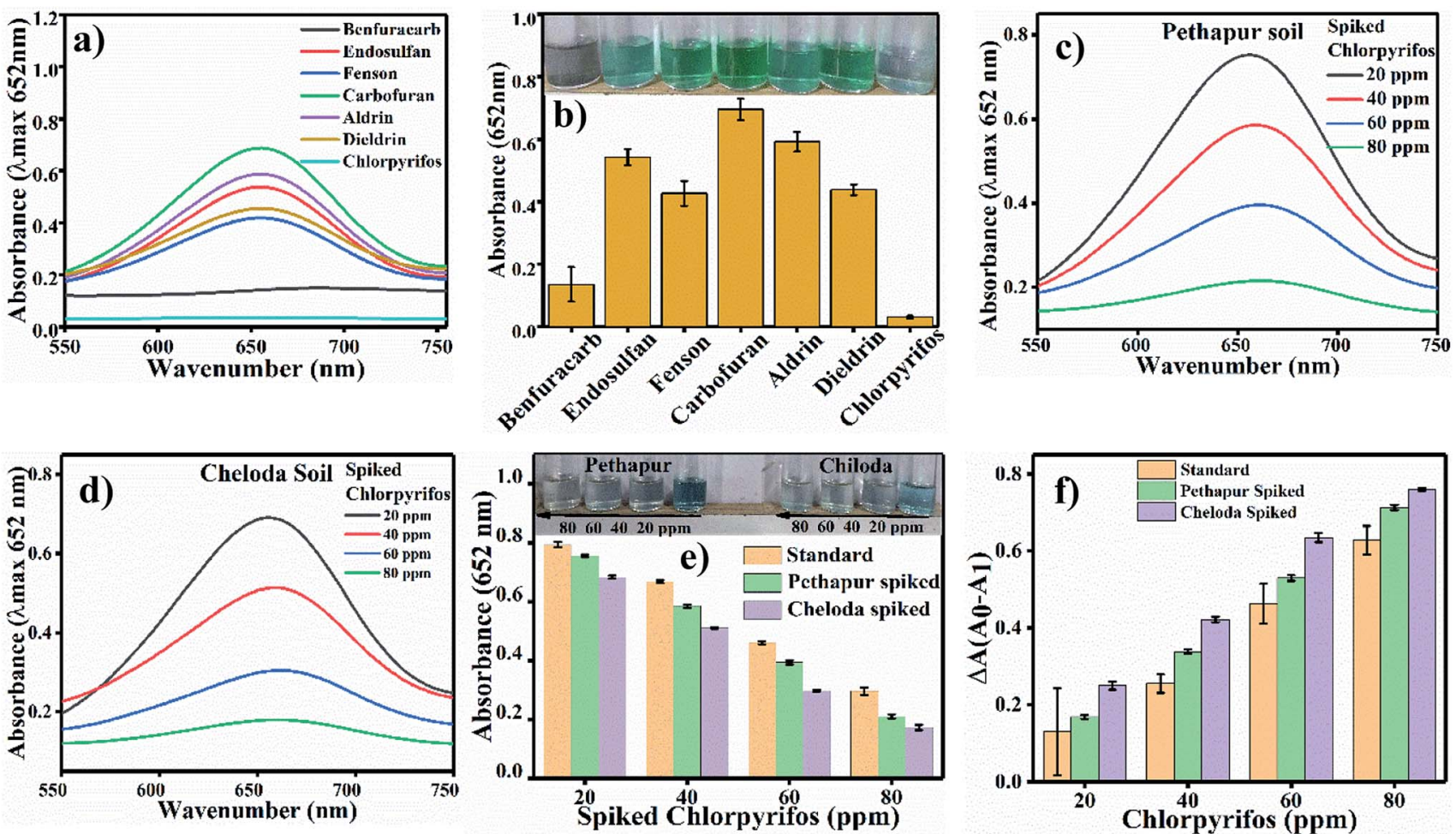

Fig. 9 (a) Selective sensing of pesticide with six other pesticides. The oxTMB maximum absorbance appears at $652 \mathrm{~nm}$ with non-oxidised TMB. (b) Bar diagram for the selectivity of the absorption of chlorpyrifos with a digital photograph of the colorimetric detection and selection. (c) Pethapur soil spiked sample, (d) Chiloda soil spiked sample and (e) comparative graph of the standard chlorpyrifos and Pethapur and Chilodaspiked soil samples. (f) $\Delta A$ graph of chlorpyrifos.

Table 2 Comparative $K_{m}$ values of oxidase mimic nanoparticles

\begin{tabular}{|c|c|c|c|c|}
\hline S. $\cdot$ no. & Enzyme & Substrate & $K_{\mathrm{m}}(\mathrm{mM})$ & Reference \\
\hline 1 & Ru NPs & TMB & 0.234 & 44 \\
\hline 2 & HRP & TMB & 0.434 & 45 \\
\hline 4 & Pt NPs & TMB & 0.096 & 47 \\
\hline 5 & $\mathrm{Ag} @ \mathrm{Ag}_{3} \mathrm{PO}_{4} \mathrm{MCs}$ & TMB & 0.11 & 28 \\
\hline 6 & Prussian blue-modified $\gamma-\mathrm{Fe}_{2} \mathrm{O}_{3}$ magnetic NPs & TMB & 0.307 & 48 \\
\hline
\end{tabular}

Vis. spectroscopic results of oxTMB in the presence and absence of IPA and BQ based on the absorbance at $652 \mathrm{~nm}$, as shown in Fig. 11b. The oxidation of TMB was found to be $\sim 16.1 \%$ reduced in the presence of IPA (reaction system 3), while in the presence of BQ, a $\sim 40.64 \%$ reduction in TMB oxidation was recorded. As a result, much fewer $\mathrm{OH}^{*}$ free radicals are being generated, but

Table 3 Analysis of real samples collected from Pethapur and Chiloda villages

\begin{tabular}{|c|c|c|c|c|}
\hline Sample & Spiked (ppm) & Detected (ppm) & Recovery (\%) & $\operatorname{RSD}(\%)(n=3)$ \\
\hline \multirow[t]{3}{*}{ Pethapur village soil sample } & 20 & 24.15388 & 120.7694 & 5.050763 \\
\hline & 40 & 52.56967 & 131.4242 & 1.480893 \\
\hline & 80 & 89.76843 & 112.2105 & 2.953513 \\
\hline \multirow[t]{2}{*}{ Chiloda village soil sample } & 20 & 35.87434 & 179.3717 & 2.896497 \\
\hline & 40 & 65.61423 & 164.0356 & 1.717815 \\
\hline
\end{tabular}



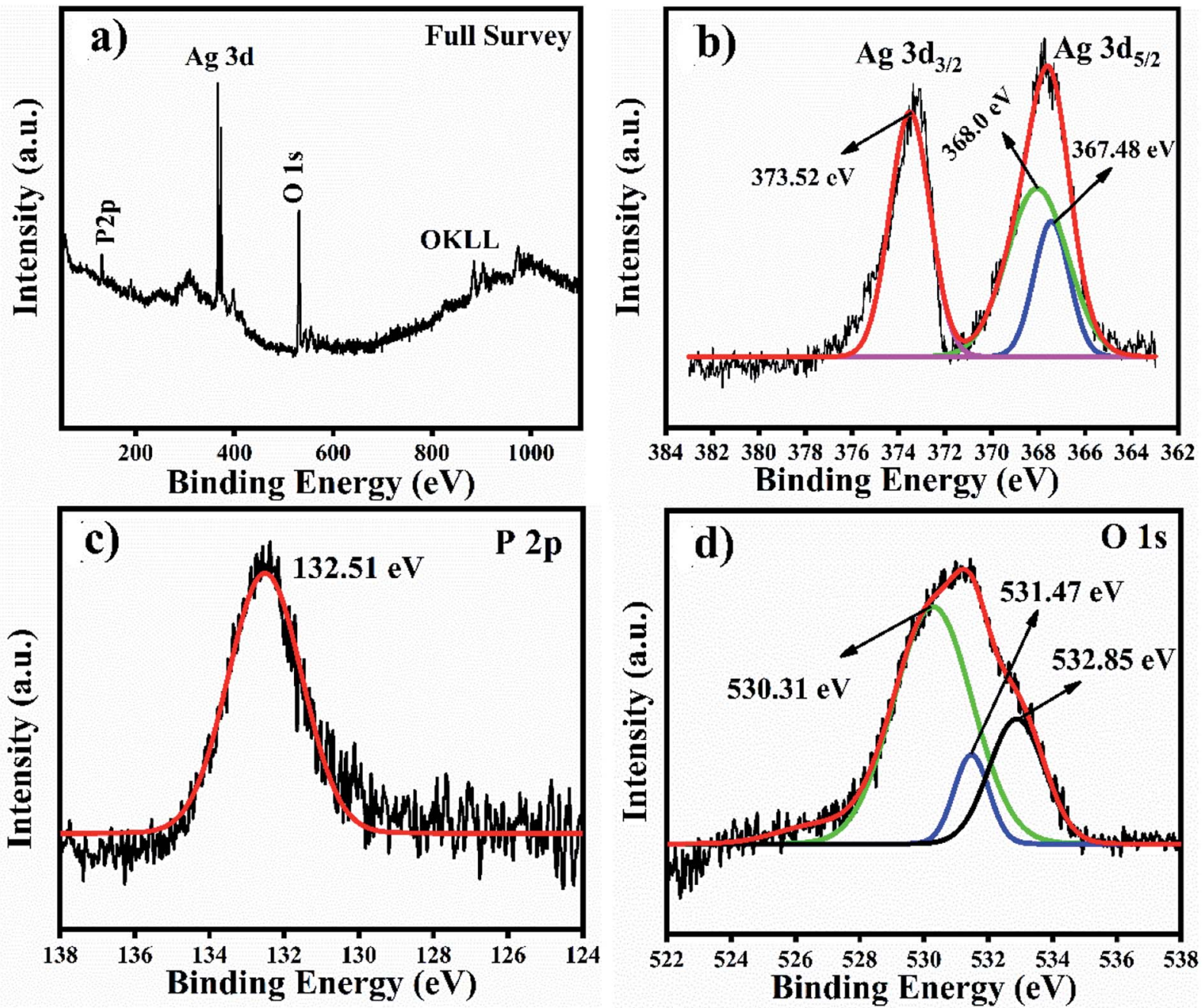

Fig. 10 XPS full survey scan and high resolution spectra of Ag, P and O spin orbit core-levels. (a) Full survey scan. (b-d) High resolution spectra of $\mathrm{Ag} \mathrm{3d,P} 2 \mathrm{p}$ and $\mathrm{O} 1 \mathrm{~s}$ spin orbit core-levels.

comparatively higher amounts of $\left(\mathrm{O}_{2}^{--}\right)$are being generated in the reaction system through an in situ process; this helps to oxidize TMB and produce a blue product. ${ }^{50}$ These results were in good agreement with our previous report on free radical validation processes. ${ }^{51}$ These results have also been added to the manuscript and highlighted in red.
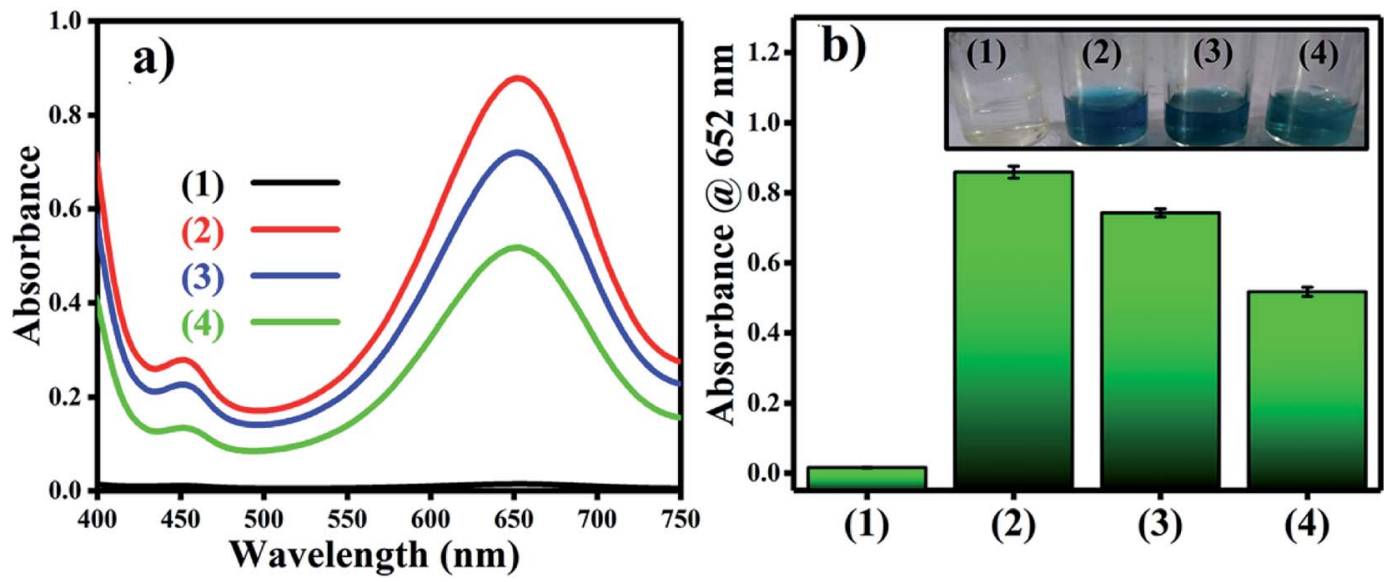

Fig. 11 Validation of free radical species using UV/Vis. spectrophotometric analysis. (a) UV/Vis. responses of different reaction systems: (1) TMB + buffer, (2) $\mathrm{TMB}+$ buffer $+\mathrm{Ag}_{3} \mathrm{PO}_{4}$, (3) $\mathrm{TMB}+$ buffer $+\mathrm{Ag}_{3} \mathrm{PO}_{4}+\mathrm{IPA}, \mathrm{TMB}+$ buffer $+\mathrm{Ag}_{3} P \mathrm{PO}_{4}+\mathrm{BQ}$. (b) Absorbances at $652 \mathrm{~nm}$ for the corresponding reaction systems. The inset of Fig. $2 \mathrm{~b}$ shows the corresponding color changes of the different reaction systems. 

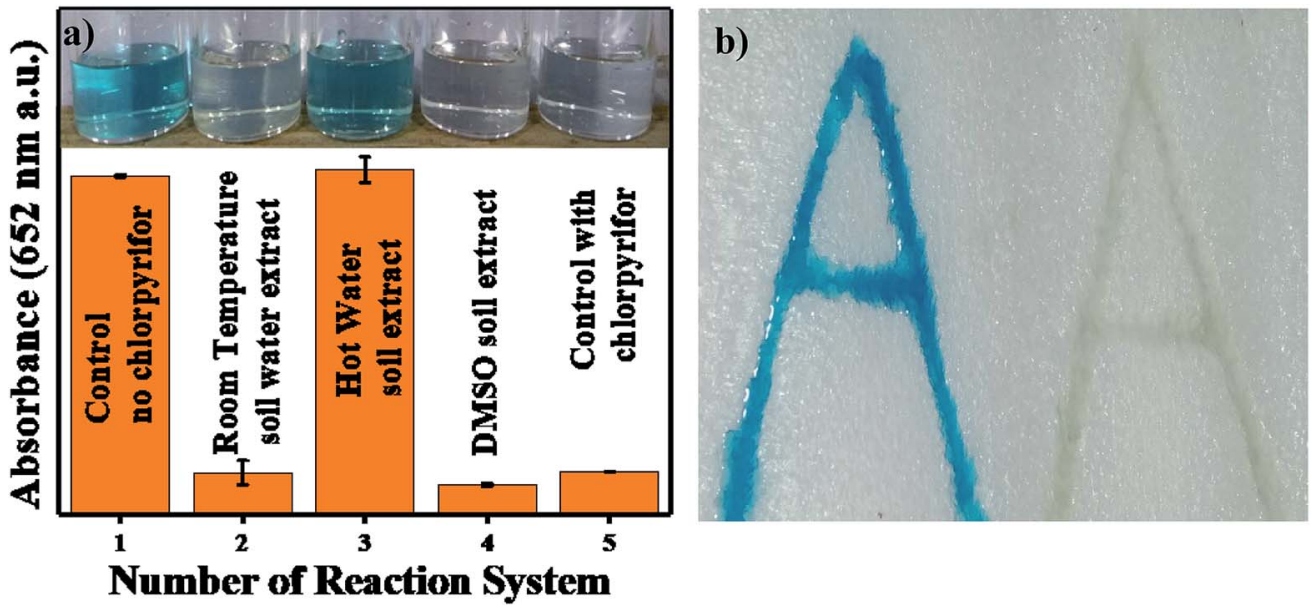

Fig. 12 (a) TMB colour comparison of control and RT water, hot water and DMSO soil extracts. (b) Thermacol imprinted images without and with chylorpyrifos.

Thermocol alphabet imprinting sensing for chlorpyrifos. In Fig. 12a, the number of reaction systems was tested. The control experiment was performed in the absence of chlorpyrifos (set 1); set 2 contained water-washed aliquot $+\mathrm{TMB}$, and set 3 contained hot water-washed aliquot $+\mathrm{TMB}$, where the appearance of blue color shows that the expected impurities and $2 \mathrm{mg} \mathrm{L}^{-1}$ of chlorpyrifos were washed out by hot water washing. In DMSO, the soluble chlorpyrifos was extracted, and further spiking experiments were performed (set 4). A control experiment in the presence of standard chlorpyrifos was also performed (set 5). In this sensing method, the alphabet letter ' $A$ ' was imprinted twice on a thermocol sheet; both imprint volumes were filled with a solution of $\mathrm{Ag}_{3} \mathrm{PO}_{4}$ NPs dissolved in water, and the water was evaporated. Only one of the imprints was filled with chlorpyrifos to discriminate the difference in the presence and absence of chlorpyrifos, and both imprints were filled with TMB. Pale blue colour was observed in the chlorpyrifos-free imprint, and colour inhibition was observed with chlorpyrifos, as shown in Fig. 12b.

\section{Conclusion}

The present work demonstrates a novel method for single-step colorimetric sensing of chlorpyrifos. $\mathrm{Ag}_{3} \mathrm{PO}_{4}$ NPs were readily synthesized and characterized by different analytical tools, showing promising oxidase catalytic properties. The $\mathrm{Ag}_{3} \mathrm{PO}_{4}$ NPs were optimized in terms of concentration, temperature, time and $\mathrm{pH}$ for superior catalytic activity. The present sensing method shows comparatively low $K_{\mathrm{m}}$ values (the lower the $K_{\mathrm{m}}$ value, the higher the sensitivity) for standard and real soil samples for chlorpyrifos detection; this indicates that the $\mathrm{Ag}_{3} \mathrm{PO}_{4}$ nanozyme is more effective than the traditional HRP enzyme. The limit of detection (LOD) of standard chlorpyrifos was found to be about $9.97 \mathrm{ppm} \cong 10 \mathrm{ppm}$ for standard samples. For real soil sample analysis, the $\mathrm{Ag}_{3} \mathrm{PO}_{4}$ NPs showed significant results for the detection of chlorpyrifos at different village sites through a spiking process. This thermocol imprinting sensing method is applicable for commercial use of the catalyst by applying this facile and inexpensive approach for sensing applications and towards device fabrication.

\section{Conflicts of interest}

There are no conflicts to declare.

\section{Acknowledgements}

The authors would like to acknowledge UGC for the financial support and Central University of Gujarat for the Central Instrument Facility. The authors would also like to acknowledge the School of Nano Sciences for providing the lab facility for experimental work.

\section{References}

1 S. Sönmez Ergün, K. Öztürk, Ö. Su, E. Başar Gürsoy, I. Uğurad and G. Yüksel, Delayed Neuropathy Due to Organophosphate Insecticide Injection in an Attempt to Commit Suicide, Hand, 2009, 4(1), 84-87, DOI: 10.1007/ s11552-008-9126-y.

2 M. Jokanović, Medical Treatment of Acute Poisoning with Organophosphorus and Carbamate Pesticides, Toxicol. Lett., 2009, 190(2), 107-115, DOI: 10.1016/ J.TOXLET.2009.07.025.

3 L. Quirós-Alcalá, A. Bradman, K. Smith, G. Weerasekera, M. Odetokun, D. B. Barr, M. Nishioka, R. Castorina, A. E. Hubbard, M. Nicas, et al., Organophosphorous Pesticide Breakdown Products in House Dust and Children's Urine, J. Exposure Sci. Environ. Epidemiol., 2012, 22(6), 559-568, DOI: 10.1038/jes.2012.46.

4 M. L. Eng, B. J. M. Stutchbury and C. A. Morrissey, Imidacloprid and Chlorpyrifos Insecticides Impair Migratory Ability in a Seed-Eating Songbird, Sci. Rep., 2017, 7(1), 1-9, DOI: 10.1038/s41598-017-15446-x. 
5 S. H. Hurlbert, Toxicity of Chlorpyrifos to Mallard Duckse, Bull. Environ. Contam. Toxicol., 1977, 17(1), 105-107, DOI: 10.1007/BF01685269.

6 R. Li, W. Wei, L. He, L. Hao, X. Ji, Y. Zhou and Q. Wang, Chlorpyrifos Residual Behaviors in Field Crops and Transfers during Duck Pellet Feed Processing, J. Agric. Food Chem., 2014, 62(42), 10215-10221, DOI: 10.1021/jf502192c.

7 A. Bhatnagar, A. S. Yadav and N. Cheema, Genotoxic Effects of Chlorpyrifos in Freshwater Fish Cirrhinus Mrigala Using Micronucleus Assay, Adv. Biol., 2016, 2016, 1-6, DOI: 10.1155/2016/9276963.

8 B. Manjunatha and G. H. Philip, Reproductive Toxicity of Chlorpyrifos Tested in Zebrafish (Danio Rerio): Histological and Hormonal End Points, Toxicol. Ind. Health, 2016, 32(10), 1808-1816, DOI: 10.1177/0748233715589445.

9 S. Rehman, S. Rehman and M. I. S. Waliullah, ChlorpyrifosInduced Neuro-Oxidative Damage in Bee, J. Toxicol. Environ. Health Sci., 2012, 4(1), 30-36, DOI: 10.1007/s13530-012-01149.

10 Y. Al, G. Codling, A. Vogt, E. Naiem, M. Mona, A. Seif and J. P. Giesy, Ecotoxicology and Environmental Safety Organophosphorus Insecticides in Honey, Pollen and Bees (Apis Melli-Fera L.) and Their Potential Hazard to Bee Colonies in Egypt, Ecotoxicol. Environ. Saf., 2015, 114, 1-8, DOI: $10.1088 / 1367-2630 / 11 / 6 / 065005$.

11 S. Zhou, C. Duan, W. H. G. Michelle, F. Yang and X. Wang, Individual and Combined Toxic Effects of Cypermethrin and Chlorpyrifos on Earthworm, J. Environ. Sci., 2011, 23(4), 676-680, DOI: 10.1016/S1001-0742(10)60462-7.

12 Y. Shao, L.-L. Wu, H.-W. Gao, F. Wang, Y. Shao, L.-L. Wu, H.-W. Gao and F. Wang, Effect of Soluble Sulfide on the Activity of Luminescent Bacteria, Molecules, 2012, 17(5), 6046-6055, DOI: 10.3390/molecules17056046.

13 A. Kumaravel and M. Chandrasekaran, Electrochemical Determination of Chlorpyrifos on a $\mathrm{Nano}^{-\mathrm{TiO}_{2}} / \mathrm{Cellulose}$ Acetate Composite Modified Glassy Carbon Electrode, $J$. Agric. Food Chem., 2015, 63(27), 6150-6156, DOI: 10.1021/ acs.jafc.5b02057.

$14 \mathrm{~K}$. Kiran, Detection of chlorpyrifos pesticide in various water samples using gold nanoparticles, Int. J. Res. Eng. Adv. Technol., 2013, 2(11), 218-221, DOI: 10.15623/ ijret.2013.0211033.

15 H. Zhang, P. Wang, Q. Zhou and Y. Wang, A Novel Method for the Detection of Chlorpyrifos by Combining Quantum Dot-Labeled Molecularly Imprinted Polymer with Flow Cytometry, Anal. Lett., 2018, 51(6), 921-934, DOI: 10.1080/ 00032719.2017.1364744.

16 C. Zhai, T. Xu, Y. Peng and Y. Li, Detection of Chlorpyrifos on Spinach Based on Surface Enhanced Raman Spectroscopy with Silver Colloids, Guang Pu Xue Yu Guang Pu Fen Xi, 2016, 36(9), 2835-2840.

17 S. Sarkar and R. Das, Presence of Chlorpyrifos Shows Blue Shift of the Absorption Peak of Silver Nanohexagons Solution - An Indication of Etching of Nanocrystals and Sensing of Chlorpyrifos, Sensor. Actuator. B Chem., 2018, 266, 149-159, DOI: 10.1016/J.SNB.2018.03.123.
18 G. Cao, X. Wu, Y. Dong, Z. Li and G. Wang, Colorimetric Determination of Melamine Based on the Reversal of the Mercury (II) Induced Inhibition of the Light-Triggered Oxidase-like Activity of Gold Nanoclusters, Microchim. Acta, 2016, 183, 441-448, DOI: 10.1007/s00604-015-1669-3.

19 S. Li, L. Wang, X. Zhang, H. Chai and Y. Huang, A Co, N CoDoped Hierarchically Porous Carbon Hybrid as a Highly Efficient Oxidase Mimetic for Glutathione Detection, Sensor. Actuator. B Chem., 2018, 264, 312-319, DOI: 10.1007/s00604-015-1669-3.

20 Y. Guo, Y. Tao, X. Ma, J. Jin, S. Wen, W. Ji and W. Song, A dual colorimetric and SERS detection of $\mathrm{Hg}^{2+}$ based on the stimulus of intrinsic oxidase-like catalytic activity of $\mathrm{Ag}$ $\mathrm{CoFe}_{2} \mathrm{O}_{4} /$ reduced graphene oxide nanocomposites, Chem. Eng. J., 2018, 350, 120-130, DOI: 10.1016/j.cej.2018.05.135.

21 A. A. Vernekar, T. Das, S. Ghosh and G. Mugesh, Enzyme Mimetics A Remarkably Efficient $\mathrm{MnFe}_{2} \mathrm{O}_{4}$-Based Oxidase Nanozyme, Chem.-Asian J., 2016, 11, 72-76, DOI: 10.1002/ asia.201500942.

22 Y. Quan, Y. Yu and J. Wang, Graphene Quantum Dot/Silver Nanoparticle Hybrids with Oxidase Activities for Antibacterial Application, ACS Biomater. Sci. Eng., 2017, 3(3), 313-321, DOI: 10.1021/acsbiomaterials.6b00644.

23 A. Asati, C. Kaittanis, S. Santra and J. M. Perez, pH-Tunable Oxidase-Like Activity of Cerium Oxide Nanoparticles Achieving Sensitive Fluorigenic Detection of Cancer Biomarkers at Neutral pH, Anal. Chem., 2011, 83(7), 25472553, DOI: 10.1021/ac102826k.

24 G. Singh, A. Kushwaha and M. Sharma, Intriguing Peroxidase-Mimic for $\mathrm{H}_{2} \mathrm{O}_{2}$ and Glucose Sensing: A Synergistic $\mathrm{Ce}_{2}\left(\mathrm{MoO}_{4}\right)_{3} / \mathrm{rGO}$ Nanocomposites, J. Alloys Compd., 2020, 825, 154134, DOI: 10.1016/ j.jallcom.2020.154134.

25 W. He, X. Han, H. Jia, J. Cai, Y. Zhou and Z. Zheng, AuPt Alloy Nanostructures with Tunable Composition and Enzyme-like Activities for Colorimetric Detection of Bisulfide, Sci. Rep., 2017, 7, 40103, DOI: 10.1038/srep40103.

26 J. Zhao, Y. Xie, W. Yuan, D. Li, S. Liu, B. Zheng and W. Hou, A Hierarchical Co - Fe LDH Rope-like Nanostructure: Facile Preparation from Hexagonal Lyotropic Liquid Crystals, $J$. Mater. Chem. B, 2013, 1263-1269, DOI: 10.1039/c2tb00389a.

27 G. L. Wang, X. F. Xu, L. H. Cao, Z. J. Li and C. Zhang, Mercury(ii)-stimulated oxidase mimetic activity of silver nanoparticles as a sensitive and selective mercury(ii) sensor, RSC Adv., 2014, 4, 5867-5872, DOI: 10.1039/ c3ra45226c.

28 D. Chai, Y. Qiu, Y. Lv, H. Liu, C. Song and G. Gao, Oxidaselike mimic of $\mathrm{Ag} @ \mathrm{Ag}_{3} \mathrm{PO}_{4}$ microcubes as a smart probe for ultrasensitive and selective $\mathrm{Hg}^{2+}$ detection, Dalton Trans., 2016, 3048-3054, DOI: 10.1039/c5dt04192a.

29 X. Xie, C. Mao, X. Liu, L. Tan, Z. Cui, X. Yang, S. Zhu, Z. Li, X. Yuan, Y. Zheng, et al., Tuning the Bandgap of PhotoSensitive Polydopamine $/ \mathrm{Ag}_{3} \mathrm{PO}_{4} / \mathrm{Graphene}$ Oxide Coating for Rapid, Noninvasive Disinfection of Implants, ACS Cent. Sci., 2018, 4(6), 724-738, DOI: 10.1021/acscentsci.8b00177.

30 M. Sharma, K. Ojha, A. Ganguly and A. K. Ganguli, $\mathrm{Ag}_{3} \mathrm{PO}_{4}$ Nanoparticle Decorated on $\mathrm{SiO}_{2}$ Spheres for Efficient 
Visible Light Photocatalysis, New J. Chem., 2015, 39(12), 9242-9248, DOI: 10.1039/C5NJ01157D.

31 J. Ma, X. Niu, J. Wang and J. Wu, Facile Synthesis of $\mathrm{Ag}_{3} \mathrm{PO}_{4}$ with the Assistance of N,N-Dimethylformamid and Urea for High Performance Photocatalysis, Catal. Commun., 2016, 77, 55-59, DOI: 10.1016/j.catcom.2016.01.021.

$32 \mathrm{H}$. Liu, D. Li, X. Yang and H. Li, Fabrication and Characterization of $\mathrm{Ag}_{3} \mathrm{PO}_{4} / \mathrm{TiO}_{2}$ Heterostructure with Improved Visible-Light Photocatalytic Activity for the Degradation of Methyl Orange and Sterilization of E.Coli, Mater. Technol., 2019, 34(4), 192-203, DOI: 10.1080/ 10667857.2018.1545391.

33 G. Botelho, J. C. Sczancoski, J. Andres, L. Gracia and E. Longo, Experimental and Theoretical Study on the Structure, Optical Properties, and Growth of Metallic Silver Nanostructures in $\mathrm{Ag}_{3} \mathrm{PO}_{4}, J$. Phys. Chem. C, 2015, 119(11), 6293-6306, DOI: 10.1021/jp512111v.

34 D. Palles, I. Konidakis, C. P. E. Varsamis and E. I. Kamitsos, Vibrational Spectroscopic and Bond Valence Study of Structure and Bonding in $\mathrm{Al}_{2} \mathrm{O}_{3}$-Containing $\mathrm{AgI}-\mathrm{Ag} \mathrm{PO}_{3}$ Glasses, RSC Adv., 2016, 6(20), 16697-16710, DOI: 10.1039/ C6RA00162A.

35 Y. Bu and Z. Chen, Role of Polyaniline on the Photocatalytic Degradation and Stability Performance of the Polyaniline/ Silver/Silver Phosphate Composite under Visible Light, ACS Appl. Mater. Interfaces, 2014, 6(20), 17589-17598, DOI: 10.1021/am503578s.

36 W. Zhang, L. Zhou, J. Shi and H. Deng, Synthesis of $\mathrm{Ag}_{3} \mathrm{PO}_{4} /$ g- $\mathrm{C}_{3} \mathrm{~N}_{4}$ Composite with Enhanced Photocatalytic Performance for the Photodegradation of Diclofenac under Visible Light Irradiation, Catalysts, 2018, 8(2), 45, DOI: 10.3390/catal8020045.

37 J. Yang, H. Wang and H. Zhang, One-Pot Synthesis of Silver Nanoplates and Charge-Transfer Complex Nanofibers, $J$. Phys. Chem. C, 2008, 112(34), 13065-13069, DOI: 10.1021/ jp802604d.

38 W. Qin, L. Su, C. Yang, Y. Ma, H. Zhang and X. Chen, Colorimetric Detection of Sulfite in Foods by a TMB- ${ }_{2}^{-}$ $\mathrm{Co}_{3} \mathrm{O}_{4}$ Nanoparticles Detection System, J. Agric. Food Chem., 2014, 62(25), 5827-5834, DOI: 10.1021/jf500950p.

39 R. Chen and P. M. Whitmore, Silver Nanoparticle Films as Hydrogen Sulfide Gas Sensors with Applications in, Art Conservation, ACS Symp. Ser., 2014, 107-120, DOI: 10.1021/ bk-2014-1183.ch006.

40 Y. Sang, Y. Huang, W. Li, J. Ren and X. Qu, Bioinspired Design of $\mathrm{Fe}^{3+}$-Doped Mesoporous Carbon Nanospheres for Enhanced Nanozyme Activity, Chem.-Eur. J., 2018, 24(28), 7259-7263, DOI: 10.1002/chem.201801010.

41 L. D. Mello, M. D. P. T. Sotomayor and L. T. Kubota, HRPBased Amperometric Biosensor for the Polyphenols
Determination in Vegetables Extract, Sensor. Actuator. B Chem., 2003, 96(3), 636-645, DOI: 10.1016/ J.SNB.2003.07.008.

42 T. Ferri, S. Maida, A. Poscia and R. Santucci, A Glucose Biosensor Based on Electro-Enzyme Catalyzed Oxidation of Glucose Using a HRP-GOD Layered Assembly, Electroanalysis, 2001, 13(14), 1198-1202, DOI: 10.1002/ 1521-4109(200110)13:14<1198::AID-ELAN1198>3.0.CO;2-H.

43 S. Nanayakkara, Z. Zhao, A. F. Patti, L. He and K. Saito, Immobilized Horseradish Peroxidase (I-HRP) as Biocatalyst for Oxidative Polymerization of 2,6-Dimethylphenol, ACS Sustainable Chem. Eng., 2014, 2(8), 1947-1950, DOI: 10.1021/sc500392k.

44 G.-J. Cao, X. Jiang, H. Zhang, T. R. Croley and J.-J. Yin, Mimicking Horseradish Peroxidase and Oxidase Using Ruthenium Nanomaterials, RSC Adv., 2017, 7(82), 5221052217, DOI: 10.1039/C7RA10370K.

45 L. Gao, J. Zhuang, L. Nie, J. Zhang, Y. Zhang, N. Gu, T. Wang, J. Feng, D. Yang, S. Perrett, et al., Intrinsic Peroxidase-like Activity of Ferromagnetic Nanoparticles, Nat. Nanotechnol., 2007, 2(9), 577-583, DOI: 10.1038/nnano.2007.260.

46 L. Wu, G. Wan, N. Hu, Z. He, S. Shi, Y. Suo, K. Wang, X. Xu, Y. Tang and G. Wang, Synthesis of Porous $\mathrm{CoFe}_{2} \mathrm{O}_{4}$ and Its Application as a Peroxidase Mimetic for Colorimetric Detection of $\mathrm{H}_{2} \mathrm{O}_{2}$ and Organic Pollutant Degradation, Nanomaterials, 2018, 8(7), 451, DOI: 10.3390/nano8070451.

47 L. Jin, Z. Meng, Y. Zhang, S. Cai, Z. Zhang, C. Li, L. Shang and Y. Shen, Ultrasmall Pt Nanoclusters as Robust Peroxidase Mimics for Colorimetric Detection of Glucose in Human Serum, ACS Appl. Mater. Interfaces, 2017, 9(11), 1002710033, DOI: 10.1021/acsami.7b01616.

48 X.-Q. Zhang, S.-W. Gong, Y. Zhang, T. Yang, C.-Y. Wang and N. Gu, Prussian Blue Modified Iron Oxide Magnetic Nanoparticles and Their High Peroxidase-like Activity, $J$. Mater. Chem., 2010, 20, 5110-5116, DOI: 10.1039/ c0jm00174k.

$49 \mathrm{X}$. Zhang and Y. Huang, Evaluation of the Antioxidant Activity of Phenols and Tannic Acid Determination with $\mathrm{Mn}_{3} \mathrm{O}_{4}$ Nano-Octahedrons as an Oxidase Mimic, Anal. Methods, 2015, 7(20), 8640-8646, DOI: 10.1039/C5AY01732G.

50 R. Prabhakar, K. B. Grant, J. Lorenzo and S. Singh, Nanomaterials Exhibiting Enzyme-Like Properties (Nanozymes): Current Advances and Future Perspectives, Front. Chem., 2019, 7, 46, DOI: 10.3389/fchem.2019.00046.

51 G. Singh, A. Kushwaha and M. Sharma, Persistent Peroxidase Mimics of Graphene Oxide Anchored Cerium Molybdate Sensor: An Effective Colorimetric Detection of $\mathrm{S}^{2-}$ and $\mathrm{Sn}^{2+}$ Ions, Microchem. J., 2019, 153, 104290, DOI: 10.1016/j.microc.2019.104290. 